\title{
2'-Hydroxyl-Protecting Groups That Are Either Photochemically Labile or Sensitive to Fluoride Ions
}

Automated chemical synthesis of RNA, like that of DNA, uses protected nucleotide monomers for construction of oligonucleotide chains. RNA monomers, however, are more difficult to obtain than their deoxy counterparts, because of the necessity of protecting their $2^{\prime}$-hydroxyl functions. This unit describes the stepwise preparation, starting from uridine, cytidine, adenosine, and guanosine, of some suitably $2^{\prime}$-protected ribonucleosides. In addition, details are given for protecting the $5^{\prime}$-hydroxyl and the nucleobase, affording ribonucleosides that can be easily converted into either phosphoramidite or phosphonate derivatives, ready to be used in a synthesizer for making RNA.

Two alternative sets of protected ribonucleosides are represented here. They are distinguished by the differing conditions required for removal of their $2^{\prime}$-protecting groups. The first consists of uridine, cytidine, adenosine, and guanosine derivatives carrying 2-nitrobenzyloxymethyl (NBOM) groups on their 2'-hydroxyls. The synthesis of these four ribonucleosides is described in Basic Protocols 1 to 4. Oligoribonucleotides synthesized from these components are deprotected by exposure to long-wave UV light (UNIT 3.7). The second set of nucleosides has its $2^{\prime}$-hydroxyls protected with tert-butyldimethylsilyl (TBDMS) groups; these can be removed from product oligoribonucleotides by treatment with tetra- $n$-butylammonium fluoride. Their syntheses are described in Alternate Protocols 1 to 4 .

CAUTION: The syntheses in these protocols involve the use of chemicals that have various degrees and kinds of toxicity. Avoid skin contact and inhalation of dusts or vapors. Most operations should be carried out in a well-vented fume hood.

NOTE: These reactions should be carried out under strictly anhydrous conditions, using anhydrous solvents and reagents. All glassware should be dried in an oven prior to use. All connections to atmospheric pressure should be through a drying tower containing a desiccant.

NOTE: For general information regarding thin-layer chromatography (TLC) or column chromatography, see APPENDIX $3 D$ and APPENDIX $3 E$, respectively.

\section{PREPARATION OF N-PROTECTED 5'-O-(4,4'-DIMETHOXYTRITYL)- 2'-O-(2-NITROBENZYLOXYMETHYL) NUCLEOSIDES}

These protocols describe the preparation of ribonucleoside derivatives that incorporate 2-nitrobenzyloxymethyl groups for protection of their 2'-hydroxyls (Figure 2.5.1). In all cases, the 2-nitrobenzyloxymethyl group is introduced into the nucleosides by means of an alkylation reaction utilizing the reagent 2-nitrobenzyl chloromethyl ether, which is prepared as required from its precursor, 2-nitrobenzyl methylthiomethyl ether (see Support Protocol 1). Before any of the nucleoside syntheses described below are carried out, an adequate stock of the methylthiomethyl ether should be accumulated.

In addition to the synthesis details, data pertaining to the $R_{\mathrm{f}}$ values from TLC (Table 2.5.1), proton nuclear magnetic resonance $\left({ }^{1} \mathrm{H}\right.$ NMR; Tables 2.5.2 and 2.5.3), and ${ }^{13} \mathrm{C} \mathrm{NMR}$ (Table 2.5.4) of the various 2-nitrobenzyloxymethyl-protected nucleosides are shown.

Contributed by Tod J. Miller, Miriam E. Schwartz, and Geoffrey R. Gough

Current Protocols in Nucleic Acid Chemistry (2000) 2.5.1-2.5.36

Copyright $\odot 2000$ by John Wiley \& Sons, Inc.

Protection of Nucleosides for Oligonucleotide Synthesis

\subsection{1}

Supplement 3 


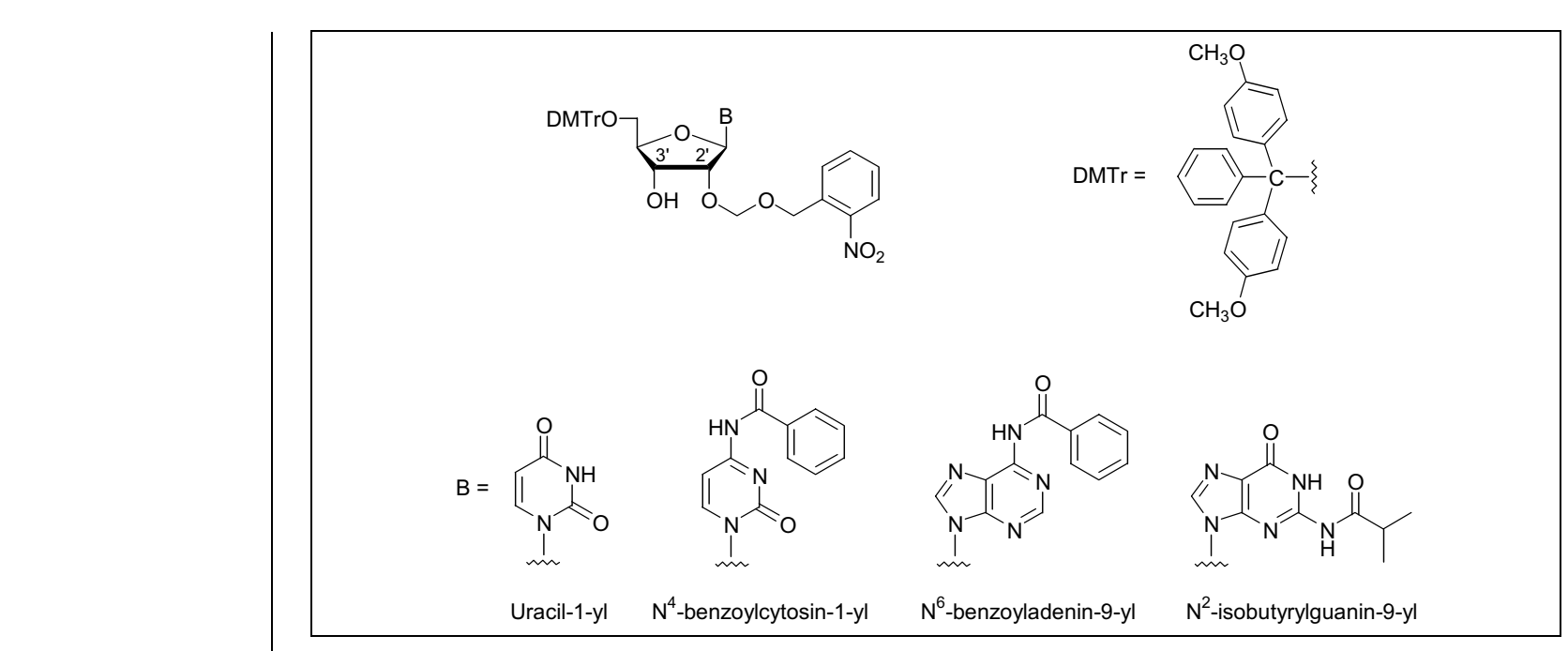

Figure 2.5.1 The four 5'-O-(4,4'-dimethoxytrityl)-2'-O-(2-nitrobenzyloxymethyl) ribonucleosides. The general structure of these ribonucleosides is in the upper-left corner and the four bases $(B)$ are shown below. DMTr is the 4,4'-dimethoxytrityl group.

These data should prove useful in confirming the identities of the products and their synthetic intermediates.

NOTE: 2-Nitrobenzyloxymethyl groups are designed to be removable by irradiation with long-wave UV light. Sunlight, or even the light emitted by standard overhead fluorescent bulbs, contains enough UV light to cause slow loss of these protecting groups. Minimize exposure of sensitive compounds by carrying out operations in an area, such as a fume hood, fitted with yellow fluorescent tubes (GE or Sylvania Golds). As an added precaution, wrap flasks and chromatography columns in aluminum foil.

2'-OH-Protecting Groups That Are Photochemically

Labile or Sensitive to

Fluoride Ions

Table 2.5.1 $R_{\mathrm{f}}$ Values of 2-Nitrobenzyloxymethyl-Protected Ribonucleosides on Merck Silica Gel $60 \mathrm{~F}_{254}$ TLC Plates

\begin{tabular}{|c|c|c|}
\hline Ribonucleoside $^{a}$ & $R_{\mathrm{f}}$ value $^{b}$ & Solvent system \\
\hline $\mathrm{U} 2^{\prime} \mathrm{NBOM}$ & 0.31 & 9:1 (v/v) chloroform/methanol \\
\hline U3NBOM & 0.31 & $9: 1(\mathrm{v} / \mathrm{v})$ chloroform/methanol \\
\hline $\mathrm{A} 2^{\prime} \mathrm{NBOM}$ & 0.42 & 9:1 (v/v) chloroform/methanol \\
\hline $\mathrm{A} 3^{\prime} \mathrm{NBOM}$ & 0.33 & 9:1 (v/v) chloroform/methanol \\
\hline $\mathrm{A}^{\mathrm{Bz} 2^{\prime} \mathrm{NBOM}}$ & 0.56 & 9:1 (v/v) chloroform/methanol \\
\hline $\mathrm{G}^{i-\mathrm{Bu}} 2^{\prime} \mathrm{NBOM}$ & 0.24 & $9: 1(\mathrm{v} / \mathrm{v})$ chloroform/methanol \\
\hline 5'DMTrU2'NBOM & 0.51 & 2:1 (v/v) ethyl acetate/hexane \\
\hline 5'DMTrU3'NBOM & 0.29 & $2: 1(\mathrm{v} / \mathrm{v})$ ethyl acetate/hexane \\
\hline 5'DMTrC2'NBOM & 0.05 & 2:1 (v/v) ethyl acetate/hexane \\
\hline $5^{\prime} \mathrm{DMTrC}^{\mathrm{Bz}} 2^{\prime} \mathrm{NBOM}$ & 0.42 & $2: 1(\mathrm{v} / \mathrm{v})$ ethyl acetate/hexane \\
\hline $5^{\prime} \mathrm{DMTr}^{\mathrm{Bz}} 2^{\prime} \mathrm{NBOM}$ & 0.56 & $2: 1(\mathrm{v} / \mathrm{v})$ ethyl acetate/hexane \\
\hline $5^{\prime} \mathrm{DMTrG}^{i-\mathrm{Bu}}{ }_{2}{ }^{\prime} \mathrm{NBOM}$ & 0.38 & 2:1 (v/v) ethyl acetate/hexane \\
\hline
\end{tabular}

${ }^{a}$ Abbreviations: A, adenosine; C, cytidine; G, guanosine; U, uridine; Bz, benzoyl; DMTr, 4,4'-dimethoxytrityl; $i$-Bu, isobutyryl; NBOM, 2-nitrobenzyloxymethyl.

${ }^{b} \mathrm{TLC} R_{\mathrm{f}}$ values are notoriously irreproducible unless measured under strictly controlled conditions. However, the relative mobilities of substances run on the same plate in the same solvent are valuable guides to compound identification. 
Table 2.5.2 ${ }^{1} \mathrm{H}-\mathrm{NMR}$ Chemical Shifts ${ }^{a}$ of Nontritylated 2-Nitrobenzyloxymethyl Ribonucleoside Derivatives $^{b}$

\begin{tabular}{|c|c|c|c|c|}
\hline Hydrogen(s) & $\mathrm{A} 2^{\prime} \mathrm{NBOM}$ & $\mathrm{A} 3^{\prime} \mathrm{NBOM}$ & $\mathrm{A}^{\mathrm{Bz}} 2^{\prime} \mathrm{NBOM}$ & $\mathrm{G}^{i-\mathrm{Bu}} 2^{\prime} \mathrm{NBOM}$ \\
\hline $\mathrm{H} 1^{\prime}$ & $6.07 \mathrm{~d}$ & $5.96 \mathrm{~d}$ & $6.12 \mathrm{~d}$ & $5.97 \mathrm{~d}$ \\
\hline $\mathrm{H} 2^{\prime}$ & $4.87 \mathrm{~m}$ & $4.85 \mathrm{~m}$ & $5.26 \mathrm{~m}$ & $5.16 \mathrm{~m}$ \\
\hline H3' & $4.34 \mathrm{bs}$ & $4.34 \mathrm{bs}$ & $4.59 \mathrm{~d}$ & $4.30 \mathrm{bs}$ \\
\hline $\mathrm{H} 4^{\prime}$ & $4.03 \mathrm{bs}$ & $4.12 \mathrm{bs}$ & $4.40 \mathrm{bs}$ & $3.97 \mathrm{bs}$ \\
\hline $\mathrm{H} 5^{\prime}$ & $3.67 \mathrm{~m}$ & $3.65 \mathrm{~m}$ & $3.98 \mathrm{~d}, 3.78 \mathrm{~d}$ & $3.61 \mathrm{~d}$ \\
\hline $\mathrm{H} 2$ or H5 & $8.02 \mathrm{~s}$ & $8.20 \mathrm{~s}$ & $8.60 \mathrm{~s}$ & $8.27 \mathrm{~s}$ \\
\hline H6 or H8 & $8.35 \mathrm{~s}$ & $8.42 \mathrm{~s}$ & $8.69 \mathrm{~s}$ & ND \\
\hline$-\mathrm{CH}_{2}-\mathrm{O}$ & $4.75 \mathrm{~s}$ & $5.04 \mathrm{~s}$ & $4.73 \mathrm{~d}$ & $4.87 \mathrm{~m}$ \\
\hline$-\mathrm{CH}_{2}-\mathrm{Ar}$ & $4.56 \mathrm{~s}$ & $5.01 \mathrm{~s}$ & $4.90 \mathrm{~m}$ & $4.71 \mathrm{bs}$ \\
\hline Ar(NBOM) & $7.3-8.0 \mathrm{~m}$ & $7.6-8.1 \mathrm{~m}$ & $7.4-8.1 \mathrm{~m}$ & $7.2-8.1 \mathrm{~m}$ \\
\hline $2^{\prime}-$ or $3^{\prime}-\mathrm{OH}$ & $5.39 \mathrm{~d}$ & $5.71 \mathrm{~d}$ & ND & ND \\
\hline $5^{\prime}-\mathrm{OH}$ & $5.53 \mathrm{bs}$ & $5.63 \mathrm{bs}$ & ND & ND \\
\hline N6-NH 2 & $7.29 \mathrm{bs}$ & $7.46 \mathrm{bs}$ & $7.26 \mathrm{bs}$ & NA \\
\hline $\mathrm{Ar}(\mathrm{Bz})$ & NA & NA & $7.3-8.1 \mathrm{~m}$ & NA \\
\hline
\end{tabular}

${ }^{a}$ The internal reference for ${ }^{1} \mathrm{H}$-NMR spectra was tetramethylsilane at $0 \mathrm{ppm}$. The solvents were dimethy sulfoxide- $d_{6}$ for the A derivatives and acetonitrile- $d_{3}$ for the $\mathrm{G}$ derivative. All shifts are measured in ppm.

${ }^{b}$ Abbreviations: A, adenosine; G, guanosine; Ar, aromatic; Bz, benzoyl; $i$-Bu, isobutyryl; NBOM, 2-nitrobenzyloxymethyl; bs, broad singlet; d, doublet; m, multiplet; s, singlet; NA, not applicable; ND, not determined.

Table 2.5.3 ${ }^{1} \mathrm{H}-\mathrm{NMR}$ Chemical Shifts ${ }^{a}$ of $5^{\prime}$-Dimethoxytritylated 2-Nitrobenzyloxymethyl Ribonucleoside Derivatives ${ }^{b}$

\begin{tabular}{|c|c|c|c|c|c|}
\hline Hydrogen(s) & $\begin{array}{l}\text { 5'DMTrU2' }^{\prime} \\
\text { NBOM }\end{array}$ & $\begin{array}{l}5^{\prime} \mathrm{DMTrC} 2^{\prime} \\
\text { NBOM }\end{array}$ & $\begin{array}{l}5^{\prime} \mathrm{DMTrC}^{\mathrm{Bz}} 2^{\prime} \\
\text { NBOM }\end{array}$ & $\begin{array}{l}5^{\prime} \mathrm{DMTrA}^{\mathrm{Bz}} 2^{\prime} \\
\text { NBOM }\end{array}$ & $\begin{array}{l}5^{\prime} \mathrm{DMTrG}^{i-\mathrm{Bu}} \\
2^{\prime} \mathrm{NBOM}\end{array}$ \\
\hline $\mathrm{H} 1^{\prime}$ & $6.06 \mathrm{~d}$ & $5.87 \mathrm{~d}$ & $6.10 \mathrm{bs}$ & $5.99 \mathrm{~d}$ & $5.99 \mathrm{~d}$ \\
\hline $\mathrm{H} 2^{\prime}$ & $4.40 \mathrm{dd}$ & $4.15 \mathrm{~d}$ & $4.58 \mathrm{~m}$ & $5.26 \mathrm{~m}$ & $5.20 \mathrm{~m}$ \\
\hline $\mathrm{H} 3^{\prime}$ & $4.51 \mathrm{~m}$ & $4.26 \mathrm{~m}$ & $4.43 \mathrm{~d}$ & $4.78 \mathrm{~d}$ & $4.60 \mathrm{dd}$ \\
\hline $\mathrm{H} 4^{\prime}$ & $4.11 \mathrm{bs}$ & $4.00 \mathrm{~d}$ & $4.19 \mathrm{~d}$ & $4.40 \mathrm{bs}$ & $4.26 \mathrm{~d}$ \\
\hline $\mathrm{H} 5^{\prime}$ & $3.56 \mathrm{bs}$ & $3.28 \mathrm{bs}$ & $3.64 \mathrm{bs}$ & $3.91 \mathrm{~m}$ & $3.48 \mathrm{~d}, 3.21 \mathrm{dd}$ \\
\hline $\mathrm{H} 2$ or $\mathrm{H} 5$ & $5.21 \mathrm{~d}$ & $5.44 \mathrm{~d}$ & $5.46 \mathrm{~d}$ & $8.72 \mathrm{~s}$ & $8.65 \mathrm{bs}$ \\
\hline H6 or H8 & $7.96 \mathrm{~d}$ & $7.79 \mathrm{~d}$ & $7.93 \mathrm{~d}$ & $8.68 \mathrm{bs}$ & ND \\
\hline$-\mathrm{OCH}_{3}$ & $3.82 \mathrm{~s}$ & $3.73 \mathrm{~s}$ & $3.86 \mathrm{~s}$ & $3.80 \mathrm{~s}$ & $3.79 \mathrm{~s}$ \\
\hline $\operatorname{Ar}(\mathrm{DMTr})$ & $6.80-7.40 \mathrm{~m}$ & $6.87-7.40 \mathrm{~m}$ & $6.80-7.50 \mathrm{~m}$ & $6.75-7.40 \mathrm{~m}$ & $6.70-7.40 \mathrm{~m}$ \\
\hline$-\mathrm{CH}_{2}-\mathrm{O}-$ & $5.00-5.15 \mathrm{bs}$ & $4.85-5.05 \mathrm{~m}$ & $5.12 \mathrm{~m}$ & $4.60 \mathrm{~m}$ & $4.81 \mathrm{~m}$ \\
\hline$-\mathrm{CH}_{2}-\mathrm{Ar}$ & $5.00-5.15 \mathrm{bs}$ & $4.85-5.05 \mathrm{~m}$ & $5.12 \mathrm{~m}$ & $4.83 \mathrm{~m}$ & $4.90 \mathrm{~m}$ \\
\hline $\operatorname{Ar}(\mathrm{NBOM})$ & $7.40-8.41 \mathrm{~m}$ & $7.57-8.08 \mathrm{~m}$ & $7.50-8.20 \mathrm{~m}$ & $7.40-8.10 \mathrm{~m}$ & $7.40-8.70 \mathrm{~m}$ \\
\hline $2^{\prime}-$ or $3^{\prime}-\mathrm{OH}$ & $5.19 \mathrm{bs}$ & $5.30 \mathrm{~d}$ & ND & ND & ND \\
\hline $\mathrm{N} 1-$ or N3-H & $10.00 \mathrm{~s}$ & NA & NA & NA & $9.28 \mathrm{~s}$ \\
\hline N4- or N6-H & NA & ND & ND & $10.00 \mathrm{~s}$ & NA \\
\hline $\operatorname{Ar}(\mathrm{Bz})$ & NA & NA & $7.10-8.70 \mathrm{~m}$ & $7.10-8.10 \mathrm{~m}$ & NA \\
\hline$i-\mathrm{Bu}-\mathrm{CH}\left(\mathrm{CH}_{3}\right)_{2}$ & NA & NA & NA & NA & $0.92 \mathrm{dd}$ \\
\hline
\end{tabular}

${ }^{a}$ The internal reference for ${ }^{1} \mathrm{H}-\mathrm{NMR}$ spectra was tetramethylsilane at $0 \mathrm{ppm}$. The solvent was chloroform- $d$. All shifts are measured in ppm.

${ }^{b}$ Abbreviations: A, adenosine; C, cytidine; G, guanosine; U, uridine; Ar, aromatic; Bz, benzoyl; DMTr, 4,4'-dimethoxytrityl; $i$-Bu, isobutyryl; NBOM, 2-nitrobenzyloxymethyl; bs, broad singlet; d, doublet; dd, doublet of doublets; m, multiplet; s, singlet; NA, not applicable; ND, not determined.

Protection of Nucleosides for Oligonucleotide Synthesis

2.5.3

Supplement 3 
Table 2.5.4 ${ }^{13} \mathrm{C}-\mathrm{NMR}$ Chemical Shifts ${ }^{a}$ of 2-Nitrobenzyloxymethyl Ribonucleoside Derivatives ${ }^{b}$

\begin{tabular}{|c|c|c|c|}
\hline Carbon & $\mathrm{A} 2^{\prime} \mathrm{NBOM}$ & $\mathrm{U} 2^{\prime} \mathrm{NBOM}$ & $\mathrm{G}^{i-\mathrm{Bu}} 2^{\prime} \mathrm{NBOM}$ \\
\hline$\overline{\mathrm{C} 1^{\prime}}$ & 86.5 & 86.4 & 86.7 \\
\hline $\mathrm{C} 2^{\prime}$ & 78.3 & 78.5 & 81.0 \\
\hline $\mathrm{C} 3^{\prime}$ & 69.3 & 68.7 & 70.3 \\
\hline $\mathrm{C} 4^{\prime}$ & 86.2 & 85.3 & 85.0 \\
\hline $\mathrm{C} 5^{\prime}$ & 61.5 & 60.6 & 61.8 \\
\hline $\mathrm{C} 2$ & 152.2 & 150.2 & 149.0 \\
\hline $\mathrm{C} 4$ & 148.7 & 163.1 & 148.4 \\
\hline $\mathrm{C} 5$ & 119.2 & 102.0 & 120.3 \\
\hline C6 & 156.0 & 140.4 & 154.9 \\
\hline $\mathrm{C} 8$ & 139.7 & NA & 137.7 \\
\hline$-\mathrm{OCH}_{2-}$ & 65.6 & 65.9 & 66.2 \\
\hline$-\mathrm{OCH}_{2}-\mathrm{Ar}$ & 94.0 & 94.1 & 95.2 \\
\hline $\operatorname{NBOM}(\mathrm{C} 1)$ & 133.6 & 133.9 & 134.3 \\
\hline NBOM (C2) & 146.6 & 147.1 & 146.5 \\
\hline NBOM (C3) & 133.3 & 133.7 & 134.0 \\
\hline NBOM (C4) & 128.1 & 128.6 & 127.9 \\
\hline NBOM (C5) & 124.3 & 124.6 & 124.7 \\
\hline NBOM (C6) & 128.3 & 128.8 & 128.7 \\
\hline$i$-Bu $\left(\mathrm{CH}_{3}\right)$ & NA & NA & 19.1 \\
\hline$i-\mathrm{Bu}\left(\mathrm{CH}_{3}\right)$ & NA & NA & 19.3 \\
\hline$i-\mathrm{Bu}(\mathrm{CH})$ & NA & NA & 35.1 \\
\hline$i-\mathrm{Bu} C=\mathrm{O}$ & NA & NA & 180.4 \\
\hline
\end{tabular}

${ }^{a}$ The internal reference for ${ }^{13} \mathrm{C}-\mathrm{NMR}$ spectra was dimethyl sulfoxide- $d_{6}$ at $39.7 \mathrm{ppm}$. The solvent was dimethyl sulfoxide- $d_{6}$. While not exhaustive, these useful and commonly observed resonances are listed with tentative assignments. All shifts are measured in ppm.

${ }^{b}$ Abbreviations: A, adenosine; G, guanosine; $\mathrm{U}$, uridine; Ar, aromatic; $i$-Bu, isobutyryl; NBOM, 2-nitrobenzyloxymethyl; NA, not applicable.

BASIC PROTOCOL 1

\footnotetext{
$2^{\prime}$-OH-Protecting Groups That Are Photochemically

Labile or Sensitive to Fluoride Ions
}

\section{Synthesis of $5^{\prime}-O-\left(4,4^{\prime}\right.$-Dimethoxytrityl)-2'-O-(2-nitrobenzyloxymethyl)uridine}

In this protocol, uridine is converted into its dibutylstannylene derivative, then alkylated using 2-nitrobenzyl chloromethyl ether. The resulting mixture of $2^{\prime}$ - and $3^{\prime}-O$-(2-nitrobenzyloxymethyl)uridine is treated with 4,4'-dimethoxytrityl chloride. The dimethoxytrityl derivatives are separated by silica-gel chromatography, affording pure $5^{\prime}-O-\left(4,4^{\prime}\right.$-dimethoxytrityl)-2'-O-(2-nitrobenzyloxymethyl)uridine. The overall reaction sequence is illustrated in Figure 2.5.2.

\section{Materials}

Methanol

Uridine

Dibutyltin oxide

Phosphorus pentoxide

Anhydrous tetra- $n$-butylammonium bromide

Anhydrous dimethylformamide, store over 4A molecular sieves

2-Nitrobenzyl chloromethyl ether, make fresh (see Support Protocol 1)

Anhydrous pyridine, store over coarse granules of calcium hydride

9:1 and 95:5 (v/v) chloroform/methanol

$66 \%(\mathrm{v} / \mathrm{v})$ aqueous pyridine

Silica gel 60, 70 to 230 mesh ASTM (e.g., EM Science) 


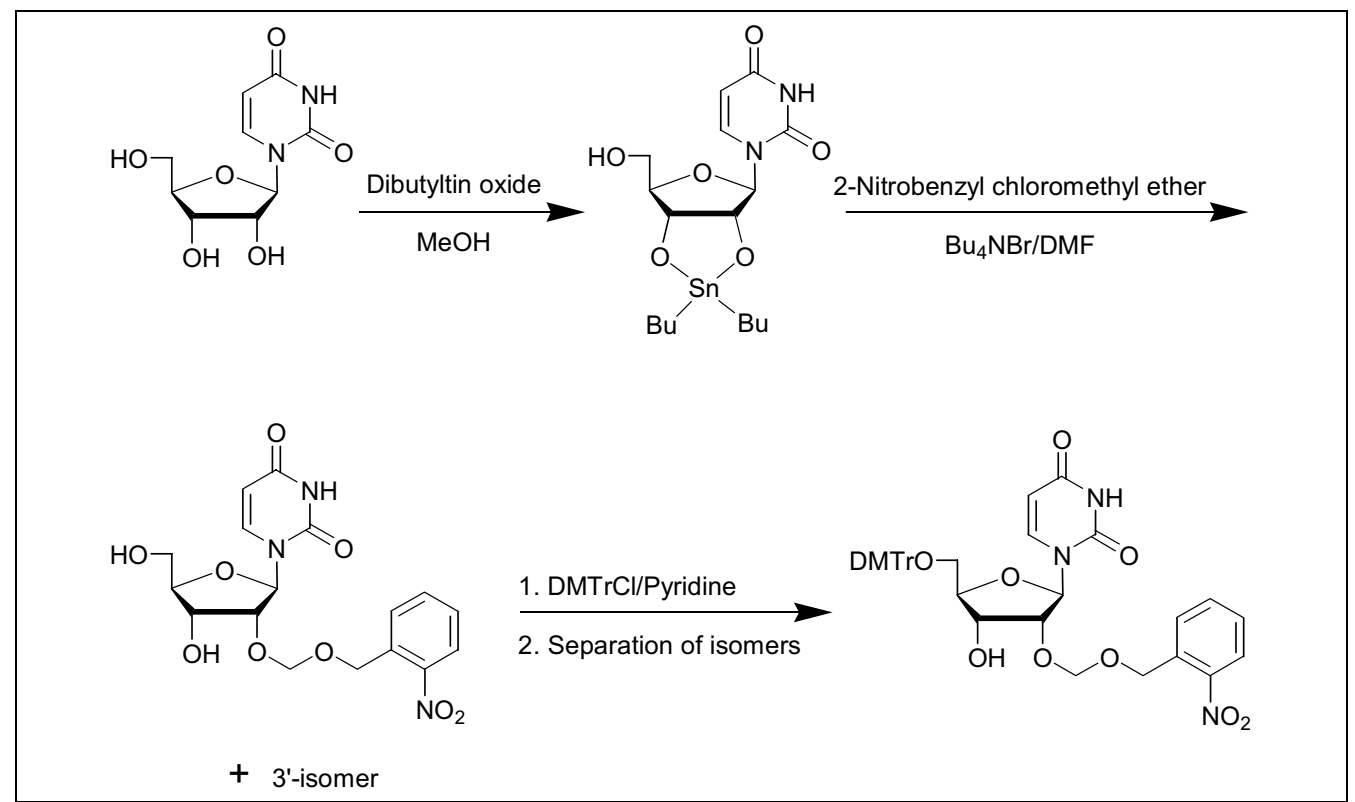

Figure 2.5.2 Preparation of 5'-O-(4,4'-dimethoxytrityl)-2'-O-(2-nitrobenzyloxymethyl)uridine from uridine. Bu is $n$-butyl.

$2.5 \times 30-\mathrm{cm}$ and $3 \times 60-\mathrm{cm}$ glass chromatography columns packed with silica gel 60, 70 to 230 mesh ASTM, in chloroform to a bed height of 25 and $50 \mathrm{~cm}$, respectively (see Support Protocol 3)

Chloroform

Anhydrous triethylamine, store over coarse granules of calcium hydride 4,4'-Dimethoxytrityl chloride

Ethyl acetate

$1 \mathrm{M} \mathrm{NaHCO}_{3}$

$2 \mathrm{M} \mathrm{NaCl}$

Anhydrous sodium sulfate

2:1 (v/v) ethyl acetate/hexane

$0 \%$ to $1 \%(\mathrm{v} / \mathrm{v})$ methanol in chloroform, containing $0.25 \%(\mathrm{v} / \mathrm{v})$ pyridine

250-mL and 2-L round-bottom flasks

Boiling chips

Water-cooled reflux condenser

Heating mantle

Rotary evaporator connected interchangeably to water aspirator and vacuum pump $50-\mathrm{mL}$ pressure-equalizing dropping funnel

Large petri plate

Filter paper, coarse porosity and fast flow rate (e.g., Quantitative Q8, Fisher)

Additional reagents and equipment for TLC and column chromatography (see Support Protocol 3)

\section{Prepare $2^{\prime}, 3^{\prime}-O$-(dibutylstannylene) uridine}

1. Add a stir-bar to $1 \mathrm{~L}$ methanol in a $2-\mathrm{L}$ round-bottom flask and begin stirring. Add $4.88 \mathrm{~g}(20 \mathrm{mmol})$ uridine and $5.00 \mathrm{~g}(20 \mathrm{mmol})$ dibutyltin oxide. 
2. Remove stir-bar, add boiling chips, and fit flask with a water-cooled reflux condenser. Heat mixture to a boil using a heating mantle, reflux $45 \mathrm{~min}$ to $1 \mathrm{hr}$, and let cool to room temperature.

3. Decant solution from boiling chips into a second 2-L flask and remove methanol using a rotary evaporator connected to a water aspirator.

4. Dry crystalline residue to constant weight in a vacuum desiccator over phosphorus pentoxide.

A yield of $9 \mathrm{~g} 2^{\prime}, 3^{\prime}-O$-(dibutylstannylene)uridine (with a melting point of $232^{\circ}$ to $234^{\circ} \mathrm{C}$ ) is expected.

If desired, this intermediate can be stored at $-20^{\circ} \mathrm{C}$ in a sealed, dry container (stable for many months).

\section{Alkylate to form 2'- and 3'-O-(2-nitrobenzyloxymethyl)uridine}

5. Add $5.10 \mathrm{~g}(10.7 \mathrm{mmol})$ dry $2^{\prime}, 3^{\prime}$-O-(dibutylstannylene)uridine and $1.72 \mathrm{~g}$ (5.35 $\mathrm{mmol}$ ) anhydrous tetra- $n$-butylammonium bromide to $40 \mathrm{~mL}$ anhydrous dimethylformamide in a $250-\mathrm{mL}$ round-bottom flask, while stirring. Fit flask with a 50-mL pressure-equalizing dropping funnel.

6. Use dropping funnel to add a freshly prepared solution of 2-nitrobenzyl chloromethyl ether (from 16 mmol 2-nitrobenzyl methylthiomethyl ether; see Support Protocol 1) dropwise over a 5-min period while stirring, then seal flask and stir $2 \mathrm{hr}$ at room temperature.

7. Add $5 \mathrm{~mL}$ anhydrous pyridine followed by $2 \mathrm{~mL}$ water and continue stirring $20 \mathrm{~min}$ at room temperature.

8. Check reaction by TLC (see Support Protocol 3) using 9:1 chloroform/methanol.

The unresolved 1:1 mixture of $2^{\prime}$ - and $3^{\prime}$-isomers will be visible under UV light as a dark band about a third of the way up the plate (Table 2.5.1).

9. Remove volatile solvents using the rotary evaporator connected to water aspirator, then continue evaporation under high vacuum (i.e., with a vacuum pump) to remove as much of the dimethylformamide as possible.

If desired, this intermediate can be stored at $-20^{\circ} \mathrm{C}$ in a sealed, dry container (stable for many months).

\section{Purify 2'- and 3'-O-(2-nitrobenzyloxymethyl)uridine}

10. Dissolve residue in the minimum volume of $66 \%$ aqueous pyridine and, using a Pasteur pipet, transfer it dropwise onto $10 \mathrm{~g}$ silica gel 60 in a large petri plate. Allow wet silica to dry in the moving airstream inside a fume hood.

An overnight drying time should be adequate if most of the dimethylformamide was removed and the minimum amount of aqueous pyridine was used.

11. Pulverize the dry, coated silica. Divide the powdery material into halves and layer them onto two $2.5 \times 30-\mathrm{cm}$ glass chromatography columns.

12. Wash each column with $100 \mathrm{~mL}$ chloroform, elute with $95: 5$ chloroform/methanol, and collect fractions as described (see Support Protocol 3).

2'-OH-Protecting Groups That Are Photochemically

Labile or Sensitive to Fluoride Ions
The volume of 95:5 chloroform/methanol should be determined from TLC results.

13. Monitor fractions by TLC using 9:1 chloroform/methanol, comparing selected fractions against samples of the original reaction mixture to locate the products. 
14. Pool and evaporate the appropriate fractions using the rotary evaporator connected to a water aspirator.

A yield of $4.2 \mathrm{~g}$ of a 1:1 mixture of the 2'- and $3^{\prime}$-isomers of (2-nitrobenzyloxymethyl)uridine is expected.

If desired, this intermediate can be stored at $-20^{\circ} \mathrm{C}$ in a sealed, dry container (stable for many months).

\section{Prepare 5'-O-(4,4'-dimethoxytrityl)-2'-O-(2-nitrobenzyloxymethyl)uridine}

15. Dry $4.2 \mathrm{~g}(10.3 \mathrm{mmol})$ mixed $2^{\prime}$ - and $3^{\prime}-O$-(2-nitrobenzyloxymethyl)uridine isomers by three co-evaporations with $30 \mathrm{~mL}$ anhydrous pyridine using the rotary evaporator connected to a vacuum pump.

16. Dissolve residue in $114 \mathrm{~mL}$ anhydrous pyridine, then add $1.60 \mathrm{~mL}(11.4 \mathrm{mmol})$ anhydrous triethylamine and $3.87 \mathrm{~g}$ (11.4 mmol) 4,4'-dimethoxytrityl chloride. Stir $3 \mathrm{hr}$ at room temperature.

17. Add $5 \mathrm{~mL}$ methanol, allow to stand $10 \mathrm{~min}$, then remove solvents on the rotary evaporator connected to a vacuum pump.

18. Dissolve residue in $250 \mathrm{~mL}$ ethyl acetate. Extract three times with $100 \mathrm{~mL}$ of $1 \mathrm{M}$ $\mathrm{NaHCO}_{3}$ and once with $100 \mathrm{~mL}$ of $2 \mathrm{M} \mathrm{NaCl}$.

CAUTION: Carbon dioxide is released during the sodium bicarbonate extractions.

19. Dry ethyl acetate layer by addition of $5 \mathrm{~g}$ anhydrous sodium sulfate, filter through filter paper to remove salt, and rotary evaporate filtrate to a yellow foam using a water aspirator.

20. Analyze this material by TLC in 2:1 ethyl acetate/hexane.

Two major bands should be visible. The upper (faster-running) one is the 2'-isomer (Table 2.5.1).

If desired, this intermediate can be stored at $-20^{\circ} \mathrm{C}$ in a sealed, dry container (stable for many months).

\section{Purify $5^{\prime}-O-\left(4,4^{\prime}\right.$-dimethoxytrityl)-2'-O-(2-nitrobenzyloxymethyl)uridine}

21. Dissolve foam $(\sim 8 \mathrm{~g})$ in 5 to $10 \mathrm{~mL}$ chloroform and add it to the top of a $3 \times 60-\mathrm{cm}$ silica gel column. Elute products from column using a 1.2-L stepwise gradient of $0 \%$ to $1 \%$ methanol in chloroform containing $0.25 \%$ pyridine as described.

22. Monitor fractions by TLC using 2:1 ethyl acetate/hexane.

Any mixed fractions containing both isomers can be rechromatographed to obtain more pure $2^{\prime}$-isomer.

Gradients of ethyl acetate in hexane may also be used for purification of these dimethoxytrityl nucleosides, as preliminary results with this alternative solvent mixture have been encouraging.

23 Combine those fractions containing the pure $2^{\prime}$-isomer, and rotary evaporate them to a foam using a water aspirator.

A yield of $40 \%$ 5'-O-(4,4'-dimethoxytrityl)-2'-O-(2-nitrobenzyloxymethyl)uridine, based on the starting quantity of uridine, is expected.

24. Store protected nucleoside in the dark at $-20^{\circ} \mathrm{C}$ in a sealed flask containing a trace of pyridine (stable for many months).

Protection of Nucleosides for Oligonucleotide Synthesis

\subsection{7}

Supplement 3 
In this protocol, $5^{\prime}-O$-(4,4'-dimethoxytrityl)-2'-O-(2-nitrobenzyloxymethyl)uridine (see Basic Protocol 1) is converted into its corresponding cytidine derivative, then selectively benzoylated with pentafluorophenyl benzoate at the N4 position. The reaction sequence is illustrated in Figure 2.5.3.

\section{Materials}

5'-O-(4,4'-Dimethoxytrityl)-2'-O-(2-nitrobenzyloxymethyl)uridine (see Basic Protocol 1)

Anhydrous pyridine, stored over coarse granules of calcium hydride

Acetic anhydride

Ethyl acetate

$1 \mathrm{M} \mathrm{NaHCO}_{3}$

$2 \mathrm{M} \mathrm{NaCl}$

Anhydrous sodium sulfate

1,2,4-Triazole

4-Chlorophenyl phosphorodichloridate

$3: 1$ (v/v) pyridine/concentrated ammonium hydroxide

$2.5 \times 30-\mathrm{cm}$ glass chromatography column packed with silica gel 60, 70 to 230 mesh ASTM, in chloroform to a bed height of $25 \mathrm{~cm}$ (see Support Protocol 3)

$0 \%$ to $1 \%$ and $0 \%$ to $4 \%(\mathrm{v} / \mathrm{v})$ methanol in chloroform, containing $0.25 \%(\mathrm{v} / \mathrm{v})$ pyridine

2:1 (v/v) ethyl acetate/hexane

Pentafluorophenyl benzoate (see Support Protocol 2)

2'-OH-Protecting Groups That Are Photochemically

Labile or Sensitive to Fluoride Ions

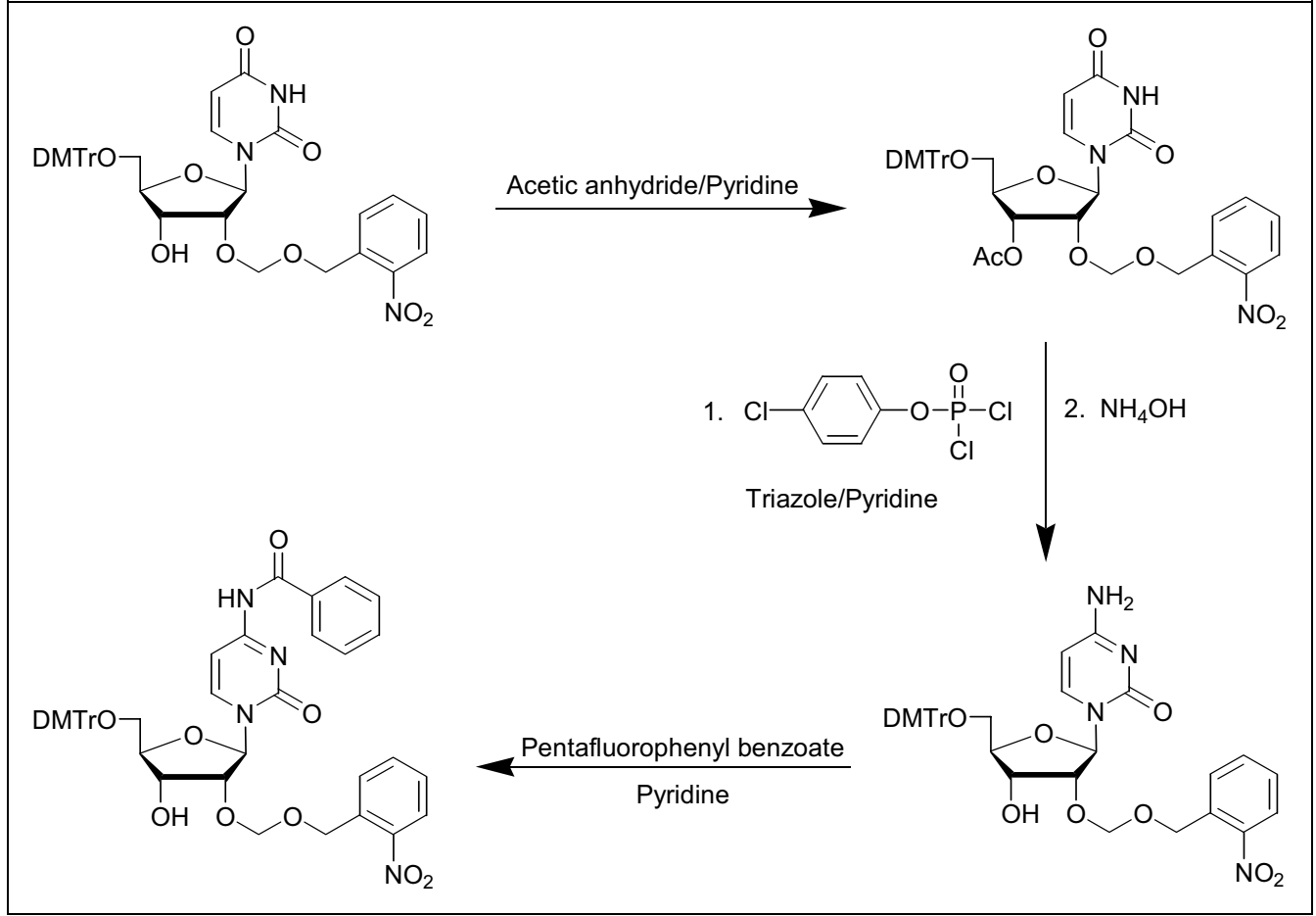

Figure 2.5.3 Preparation of $5^{\prime}-O-\left(4,4^{\prime}\right.$-dimethoxytrityl)-2'-O-(2-nitrobenzyloxymethyl)- $N^{4}$-benzoylcytidine from $5^{\prime}-O-\left(4,4^{\prime}\right.$-dimethoxytrityl)-2'-O-(2-nitrobenzyloxymethyl)uridine. 
250- and 500-mL separatory funnels

Filter paper, coarse porosity and fast flow rate (e.g., Quantitative Q8, Fisher)

Rotary evaporator connected interchangeably to water aspirator and vacuum pump

$10-$ and $25-\mathrm{mL}$ round-bottom flasks

Additional reagents and equipment for TLC and column chromatography (see Support Protocol 3)

\section{Protect 3'-hydroxyl of $5^{\prime}-O-\left(4,4^{\prime}\right.$-dimethoxytrityl $)-2^{\prime}-O$ - (2-nitrobenzyloxymethyl)uridine}

1. Add $580 \mathrm{mg}(0.82 \mathrm{mmol})$ 5'-O-(4,4'-dimethoxytrityl)-2'-O-(2-nitrobenzyloxymethyl)uridine to a flask containing $3 \mathrm{~mL}$ anhydrous pyridine and stir to dissolve.

2. Add $1.64 \mathrm{~mL}(17 \mathrm{mmol})$ acetic anhydride and allow reaction mixture to stand $2 \mathrm{hr}$ at room temperature.

3. Cool flask in an ice bath and add $2.5 \mathrm{~mL}$ anhydrous pyridine, followed by dropwise addition over a 5-min period of $4 \mathrm{~mL}$ water, while stirring and cooling continuously.

4. Add an additional $1 \mathrm{~mL}$ anhydrous pyridine to redissolve any precipitate, and allow solution to stand $18 \mathrm{hr}$ at room temperature in the dark.

5. Transfer mixture to a $250-\mathrm{mL}$ separatory funnel using $50 \mathrm{~mL}$ ethyl acetate and extract the organic layer three times with $50 \mathrm{~mL}$ of $1 \mathrm{M} \mathrm{NaHCO}_{3}$ and three times with 50 $\mathrm{mL}$ of $2 \mathrm{M} \mathrm{NaCl}$.

CAUTION: Carbon dioxide is released during the sodium bicarbonate extractions.

The 3'-hydroxyl is temporarily protected as an acetate ester.

\section{Prepare 5'-O-(4,4'-dimethoxytrityl)-2'-O-(2-nitrobenzyloxymethyl)cytidine}

6 . Dry ethyl acetate layer over $3 \mathrm{~g}$ anhydrous sodium sulfate, filter through filter paper to remove salt, and evaporate filtrate to a foam using a rotary evaporator connected to a water aspirator.

7. Co-evaporate the product three times with $10 \mathrm{~mL}$ anhydrous pyridine in a $25-\mathrm{mL}$ round-bottom flask using the rotary evaporator connected to a vacuum pump. Dissolve final residue in $2.7 \mathrm{~mL}$ anhydrous pyridine.

8. Add $314 \mathrm{mg}$ (4.54 mmol) 1,2,4-triazole, stir to dissolve ( $\sim \mathrm{hr}$ ), then add $0.36 \mathrm{~mL}$ (2.2 mmol) 4-chlorophenyl phosphorodichloridate. Stir $1 \mathrm{hr}$ and then let stand $72 \mathrm{hr}$ at room temperature in the dark.

9. Cool flask in an ice bath and add $0.2 \mathrm{~mL}$ water while stirring. Stir $30 \mathrm{~min}$ at $0^{\circ} \mathrm{C}$, then add $3 \mathrm{~mL}$ anhydrous pyridine.

10. Use a disposable Pasteur pipet to add the resulting solution dropwise to $80 \mathrm{~mL}$ of $3: 1$ pyridine/concentrated ammonium hydroxide while stirring. Loosely stopper the container and allow reaction mixture to stand $48 \mathrm{hr}$ at room temperature in the dark.

11. Concentrate solution to a slurry by rotary evaporation using a water aspirator and transfer to a 500-mL separatory funnel using $150 \mathrm{~mL}$ ethyl acetate.

12. Extract three times with $100 \mathrm{~mL}$ of $1 \mathrm{M} \mathrm{NaHCO}_{3}$, then three times with $100 \mathrm{~mL}$ of $2 \mathrm{M} \mathrm{NaCl}$.

13. Repeat step 6.

Protection of Nucleosides for Oligonucleotide Synthesis

2.5.9 
14. Layer residue on a $2.5 \times 30-\mathrm{cm}$ silica gel column and elute products using a $1-\mathrm{L}$ stepwise gradient of $0 \%$ to $4 \%$ methanol in chloroform containing $0.25 \%$ pyridine as described (see Support Protocol 3).

15. Monitor fractions by TLC (see Support Protocol 3) using 2:1 ethyl acetate/hexane.

16. Evaporate appropriate fractions using the rotary evaporator connected to a water aspirator to produce the pure product, $5^{\prime}-O-\left(4,4^{\prime}\right.$-dimethoxytrityl)-2'-O-(2-nitrobenzyloxymethyl)cytidine.

A $71 \%$ yield, based on the starting quantity of $5^{\prime}-O-\left(4,4^{\prime}\right.$-dimethoxytrityl)-2'-O-(2-nitrobenzyloxymethyl)uridine, is expected.

If desired, this intermediate can be stored at $-20^{\circ} \mathrm{C}$ in a sealed, dry container (stable for many months).

Prepare 5'-O-(4,4'-dimethoxytrityl)-2'-O-(2-nitrobenzyloxymethyl)- $N^{4}$ -

\section{benzoylcytidine}

17. Dissolve $412 \mathrm{mg}(0.58 \mathrm{mmol})$ 5'-O-(4,4'-dimethoxytrityl)-2'-O-(2-nitrobenzyloxymethyl)cytidine in $1 \mathrm{~mL}$ anhydrous pyridine in a $10-\mathrm{mL}$ round-bottom flask.

18. Add $251 \mathrm{mg}(0.87 \mathrm{mmol})$ pentafluorophenyl benzoate and swirl flask to dissolve. Seal flask and allow solution to stand 6 days at room temperature in the dark.

19. Examine mixture by TLC using 2:1 ethyl acetate/hexane, comparing it to the starting material to confirm complete conversion to the $N$-benzoyl derivative.

20. Transfer reaction mixture to a $250-\mathrm{mL}$ separatory funnel using $100 \mathrm{~mL}$ ethyl acetate, then extract as in step 5 .

21. Repeat step 6.

22. Repeat steps 14 to 16 , using a $1.2-\mathrm{L}$ stepwise gradient of $0 \%$ to $1 \%$ methanol in chloroform containing $0.25 \%$ pyridine in step 14 .

A $91 \%$ yield based on the starting quantity of $5^{\prime}-O-\left(4,4^{\prime}\right.$-dimethoxytrityl)-2'-O-(2-nitrobenzyloxymethyl)cytidine is expected.

23. Store protected nucleoside in the dark at $-20^{\circ} \mathrm{C}$ in a sealed flask containing a trace of pyridine (stable for many months).

BASIC PROTOCOL 3

\footnotetext{
2'-OH-Protecting Groups That Are Photochemically

Labile or Sensitive to Fluoride Ions
}

\section{Synthesis of $5^{\prime}-O$-(4,4'-Dimethoxytrityl)-2'-O-(2-nitrobenzyloxymethyl)- $N^{6}$-benzoyl- adenosine}

In this protocol, adenosine is converted into its dibutylstannylene derivative, then alkylated with 2-nitrobenzyl chloromethyl ether, and the resulting $2^{\prime}$ - and $3^{\prime}-O$-(2-nitrobenzyloxymethyl)adenosines are separated by column chromatography. Benzoylation at the N6 position (to protect the nucleobase), followed by dimethoxytritylation (to protect the 5'-hydroxyl), completes the synthesis. The reaction sequence is illustrated in Figure 2.5.4.

\section{Materials}

Methanol

Adenosine

Dibutyltin oxide

Phosphorous pentoxide

Anhydrous tetra- $n$-butylammonium bromide

Anhydrous dimethylformamide, stored over 4A molecular sieves

2-Nitrobenzyl chloromethyl ether, make fresh (see Support Protocol 1) 

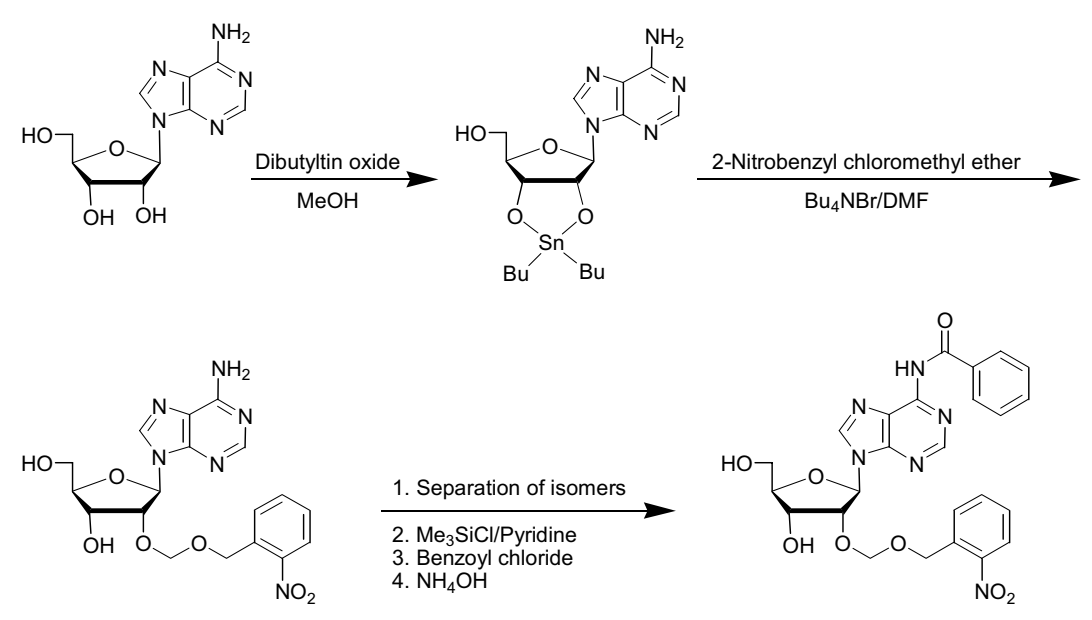

$+3^{\prime}$-isomer

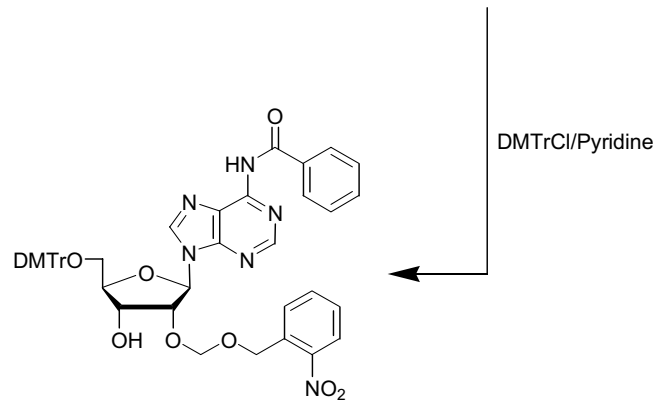

Figure 2.5.4 Preparation of $5^{\prime}-O-\left(4,4^{\prime}\right.$-dimethoxytrityl)-2'-O-(2-nitrobenzyloxymethyl)- $N^{6}$-benzoyladenosine from adenosine. Bu is $n$-butyl.

Anhydrous pyridine, store over coarse granules of calcium hydride

9:1 and 95:5 (v/v) chloroform/methanol

$66 \%(\mathrm{v} / \mathrm{v})$ aqueous pyridine

Silica gel 60, 70 to 230 mesh ASTM (e.g., EM Science)

$2.5 \times 25-\mathrm{cm}, 2.5 \times 30-\mathrm{cm}$, and $3 \times 60-\mathrm{cm}$ glass chromatography columns packed

with silica gel 60, 70 to 230 mesh ASTM, in chloroform (see Support Protocol 3)

$1 \%$ to $5 \%(\mathrm{v} / \mathrm{v})$ methanol in chloroform

$80 \%(\mathrm{v} / \mathrm{v})$ aqueous acetonitrile

Acetonitrile

Trimethylchlorosilane

Benzoyl chloride

Concentrated ammonium hydroxide

Ethyl acetate

$1 \mathrm{M} \mathrm{NaHCO}_{3}$

$2 \mathrm{M} \mathrm{NaCl}$

Anhydrous sodium sulfate

Chloroform

Triethylamine, stored over coarse granules of calcium hydride

4,4'-Dimethoxytrityl chloride

$0 \%$ to $1 \%(\mathrm{v} / \mathrm{v})$ methanol in chloroform containing $0.25 \%(\mathrm{v} / \mathrm{v})$ pyridine

2:1 (v/v) ethyl acetate/hexane

100-mL, 250-mL, and 2-L round-bottom flasks

Boiling chips

Water-cooled reflux condenser

Heating mantle

Protection of

Nucleosides for

Oligonucleotide

Synthesis

\subsubsection{1}

Supplement 3 
Rotary evaporator connected interchangeably to water aspirator and vacuum pump Oil bath, $60^{\circ} \mathrm{C}$

50 -mL pressure-equalizing dropping funnel

500 -mL separatory funnel

Filter paper, coarse porosity and fast flow rate (e.g., Quantitative Q8, Fisher)

Additional reagents and equipment for TLC and column chromatography (see Support Protocol 3)

\section{Prepare 2',3'-O-(dibutylstannylene)adenosine}

1. Add a stir-bar to $700 \mathrm{~mL}$ methanol in a 2-L round-bottom flask and begin stirring. Add $6.7 \mathrm{~g}(25 \mathrm{mmol})$ adenosine and $6.25 \mathrm{~g}(25 \mathrm{mmol})$ dibutyltin oxide.

2. Remove stir-bar, add boiling chips, and fit flask with a water-cooled reflux condenser. Heat mixture to boiling using a heating mantle, reflux $45 \mathrm{~min}$, and let cool to room temperature.

3. Decant solution from boiling chips into a second 2-L flask and remove methanol using a rotary evaporator connected to a water aspirator.

4. Dry residue to constant weight in a vacuum desiccator over phosphorus pentoxide.

A yield of $10.5 \mathrm{~g}$ is expected.

If desired, this intermediate can be stored at $-20^{\circ} \mathrm{C}$ in a sealed, dry container (stable for many months).

\section{Alkylate to form 2'- and 3'-O-(2-nitrobenzyloxymethyl)adenosine}

5. Add $8 \mathrm{~g}$ (16 mmol) dry $2^{\prime}, 3^{\prime}-O$-(dibutylstannylene)adenosine and $\left.7.7 \mathrm{~g} \mathrm{(16} \mathrm{mmol}\right)$ anhydrous tetra- $n$-butylammonium bromide to $65 \mathrm{~mL}$ anhydrous dimethylformamide in a $250-\mathrm{mL}$ round-bottom flask while stirring.

6. Heat to $60^{\circ} \mathrm{C}$ in an oil bath and fit flask with a $50-\mathrm{mL}$ pressure-equalizing dropping funnel.

7. Use the dropping funnel to add freshly prepared 2-nitrobenzyl chloromethyl ether (from $16 \mathrm{mmol}$ 2-nitrobenzyl methylthiomethyl ether; see Support Protocol 1) dropwise over a 5-min period while stirring at $60^{\circ} \mathrm{C}$. Seal flask and stir $1 \mathrm{hr}$ at $60^{\circ} \mathrm{C}$.

8. Add $20 \mathrm{~mL}$ anhydrous pyridine and stir $25 \mathrm{~min}$ at room temperature.

9. Examine reaction mixture by TLC (see Support Protocol 3) in 9:1 chloroform/methanol.

The 2'-and $3^{\prime}$-isomers are visible as two closely spaced bands in the lower half of the plate. The upper band of this pair is the $2^{\prime}$-isomer (Table 2.5.1).

10. Remove solvents by rotary evaporation, using high vacuum (i.e., with a vacuum pump) to remove as much dimethylformamide as possible.

If desired, this intermediate can be stored at $-20^{\circ} \mathrm{C}$ in a sealed, dry container (stable for many months).

\section{Purify 2'-O-(2-nitrobenzyloxymethyl)adenosine}

2'-OH-Protecting Groups That Are Photochemically Labile or Sensitive to Fluoride Ions 
An overnight drying time should be adequate if most of the dimethylformamide was removed and the minimum amount of aqueous pyridine was used.

12. Pulverize the dry, coated silica. Layer powder onto a $3 \times 60-\mathrm{cm}$ glass chromatography column and elute with 95:5 chloroform/methanol, collecting fractions as described (see Support Protocol 3).

The volume of 95:5 chloroform/methanol should be determined from TLC results.

13. Monitor fractions by TLC in 9:1 chloroform/methanol.

14. Combine all fractions containing the 2 '-isomer and rotary evaporate to dryness using a water aspirator.

If desired, this intermediate can be stored at $-20^{\circ} \mathrm{C}$ in a sealed, dry container (stable for many months).

15. Dry material on $6 \mathrm{~g}$ silica gel 60 as in step 11 and repeat step 12 using a 1-L stepwise gradient of $1 \%$ to $5 \%$ methanol in chloroform (beginning with $200 \mathrm{~mL}$ of $1 \%$ methanol, followed by $200 \mathrm{~mL}$ of $2 \%$ methanol, and so on).

16. Repeat steps 13 and 14.

2'-O-(2-Nitrobenzyloxymethyl)adenosine contaminated with a trace of the 3'-isomer is left after solvent removal.

If desired, this intermediate can be stored at $-20^{\circ} \mathrm{C}$ in a sealed, dry container (stable for many months).

17. Dissolve residue in a minimal amount of $80 \%$ aqueous acetonitrile with heating, then use the rotary evaporator connected to water aspirator to repeatedly co-evaporate with acetonitrile to a final volume of $\sim 5 \mathrm{~mL}$ until crystallization of the $2^{\prime}$-isomer occurs.

A $24 \%$ yield of white crystals is obtained, based on the starting quantity of 2', $3^{\prime}-O$-(dibutylstannylene)adenosine. This material may be further recrystallized from water. The melting point of the product is $175^{\circ}$ to $177^{\circ} \mathrm{C}$.

If desired, this intermediate can be stored at $-20^{\circ} \mathrm{C}$ in a sealed, dry container (stable for many months).

\section{Prepare 2'-O-(2-nitrobenzyloxymethyl)- $N^{6}$-benzoyladenosine}

18. Add $1.08 \mathrm{~g}$ (2.5 mmol) $2^{\prime}$ - $O$-(2-nitrobenzyloxymethyl)adenosine to $10 \mathrm{~mL}$ anhydrous pyridine in a 100-mL round-bottom flask while stirring to dissolve. Add 1.59 $\mathrm{mL}(12.5 \mathrm{mmol})$ trimethylchlorosilane, seal flask, and stir $2 \mathrm{hr}$ at room temperature.

19. Add $1.45 \mathrm{~mL}(12.5 \mathrm{mmol})$ benzoyl chloride and reseal flask. Stir $2 \mathrm{hr}$, then cool to $0^{\circ} \mathrm{C}$ and add $2.5 \mathrm{~mL}$ water. Stir $10 \mathrm{~min}$, then add $5 \mathrm{~mL}$ concentrated ammonium hydroxide. Cover (do not seal) flask and stir $30 \mathrm{~min}$ at room temperature.

Ammonium hydroxide from a newly opened bottle should be used, and the reaction should be checked with $\mathrm{pH}$ paper to make certain it remains alkaline throughout the $30 \mathrm{~min}$. More ammonium hydroxide should be added in 1-mL aliquots, if necessary, to maintain alkalinity.

20. Remove ammonia and solvents by rotary evaporation using a water aspirator.

21. Transfer reaction mixture to a $500-\mathrm{mL}$ separatory funnel using $150 \mathrm{~mL}$ ethyl acetate and extract three times with $100 \mathrm{~mL}$ of $1 \mathrm{M} \mathrm{NaHCO}_{3}$, then three times with $100 \mathrm{~mL}$ of $2 \mathrm{M} \mathrm{NaCl}$.

22. Dry ethyl acetate layer over $5 \mathrm{~g}$ anhydrous sodium sulfate, filter through filter paper to remove salt, and rotary evaporate filtrate using a water aspirator.

Protection of Nucleosides for Oligonucleotide Synthesis

\subsubsection{3}

Supplement 3 
If desired, this intermediate can be stored at $-20^{\circ} \mathrm{C}$ in a sealed, dry container (stable for many months).

23. Layer residue on a $2.5 \times 25-\mathrm{cm}$ silica gel column and elute with $100 \mathrm{~mL}$ chloroform, followed by $300 \mathrm{~mL}$ of $1 \%$ methanol in chloroform and $800 \mathrm{~mL}$ of $2 \%$ methanol in chloroform as described (see Support Protocol 3).

24. Monitor fractions by TLC using 9:1 chloroform/methanol.

25. Use the rotary evaporator connected to a water aspirator to evaporate appropriate fractions and produce $2^{\prime}-O$-(2-nitrobenzyloxymethyl)- $N^{6}$-benzoyladenosine.

A yield of $88 \%$, based on the starting quantity of 2'-O-(2-nitrobenzyloxymethyl)adenosine, is expected.

If desired, this intermediate can be stored at $-20^{\circ} \mathrm{C}$ in a sealed, dry container (stable for many months).

\section{Prepare 5'-O-(4,4'-dimethoxytrityl)-2'-O-(2-nitrobenzyloxymethyl)- $\mathrm{N}^{6}$ -} benzoyladenosine

26. Dry $1.05 \mathrm{~g}$ (1.96 mmol) 2'-O-(2-nitrobenzyloxymethyl)- $N^{6}$-benzoyladenosine by three co-evaporations with $30 \mathrm{~mL}$ anhydrous pyridine using the rotary evaporator connected to a vacuum pump.

27. Dissolve residue in $30 \mathrm{~mL}$ anhydrous pyridine, then add $0.34 \mathrm{~mL}(2.4 \mathrm{mmol})$ triethylamine and $0.80 \mathrm{~g}$ (2.4 mmol) 4,4'-dimethoxytrityl chloride. Stir $3 \mathrm{hr}$ at room temperature.

28. Add $1 \mathrm{~mL}$ methanol and, after $10 \mathrm{~min}$, remove solvents by rotary evaporation using a vacuum pump.

29. Repeat steps 21 to 25 with the following exceptions:

a. Extract three times with $\mathrm{NaHCO}_{3}$ but only once with $\mathrm{NaCl}$ in step 21 .

b. Use a $2.5 \times 30-\mathrm{cm}$ silica gel column and a $1.2-\mathrm{L}$ stepwise gradient of $0 \%$ to $1 \%$ methanol in chloroform containing $0.25 \%$ pyridine in step 23 .

c. Use 2:1 ethyl acetate/hexane for TLC in step 24.

The yield of $5^{\prime}-O-\left(4,4^{\prime}\right.$-dimethoxytrityl)-2'-O-(2-nitrobenzyloxymethyl)- $N^{6}$-benzoyladenosine is expected to be $91 \%$ based on the starting quantity of 2'-O-(2-nitrobenzyloxymethyl)- $N^{6}$-benzoyladenosine.

30. Store $5^{\prime}-O-\left(4,4^{\prime}\right.$-dimethoxytrityl)-2'-O-(2-nitrobenzyloxymethyl)- $N^{6}$-benzoyladenosine in the dark at $-20^{\circ} \mathrm{C}$ in a sealed container containing a trace of pyridine (stable for many months).

BASIC PROTOCOL 4

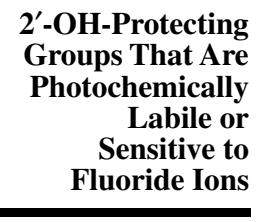

2.5.14 


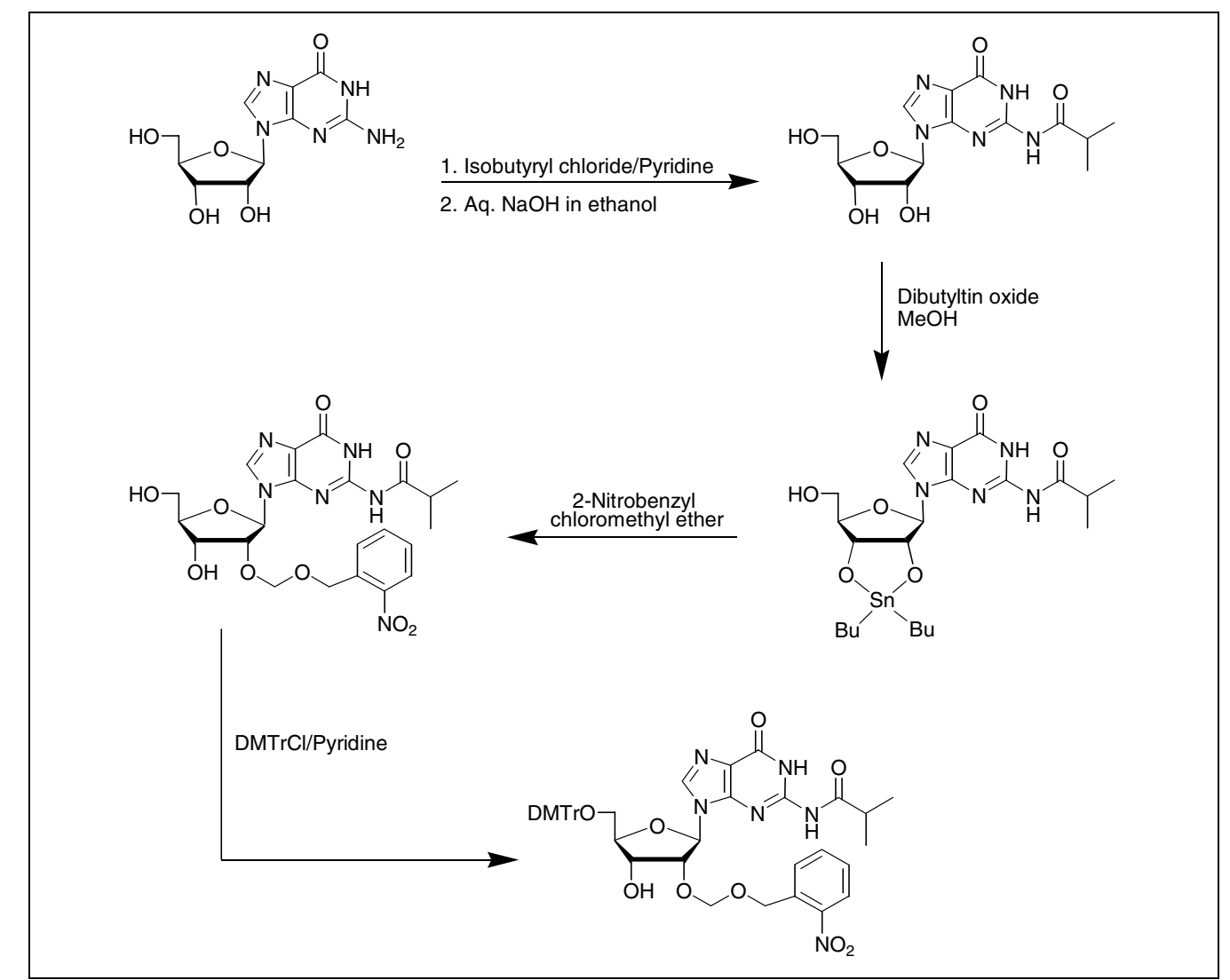

Figure 2.5.5 Preparation of $5^{\prime}-O-\left(4,4^{\prime}\right.$-dimethoxytrityl)-2'-O-(2-nitrobenzyloxymethyl)- $N^{2}$-isobutyrylguanosine from guanosine. Bu is $n$-butyl.

\section{Materials}

Guanosine hydrate

Anhydrous pyridine, stored over coarse granules of calcium hydride

Isobutyryl chloride

Ethyl acetate

$1 \mathrm{M} \mathrm{NaHCO}_{3}$

$2 \mathrm{M} \mathrm{NaCl}$

Anhydrous sodium sulfate

Ethanol

$2 \mathrm{~N} \mathrm{NaOH}$, ice cold

Dowex AG50W-X8 ion exchange resin (pyridinium form)

$5 \times 60-\mathrm{cm}$ glass chromatography column filled with $50 \mathrm{~mL}$ Dowex AG50W-X8 ion-exchange resin (pyridinium form) in water

4:1 (v/v) chloroform/methanol

Phosphorus pentoxide

Dibutyltin oxide

Methanol

Anhydrous dimethylformamide, stored over 4A molecular sieves

2-Nitrobenzyl chloromethyl ether, make fresh (see Support Protocol 1)

Silica gel 60, 70 to 230 mesh ASTM (e.g., EM Science)

$2.5 \times 25-\mathrm{cm}$ and $2.5 \times 30-\mathrm{cm}$ glass chromatography columns packed with silica gel 60, 70 to 230 mesh ASTM, in chloroform to a bed height of 20 and $25 \mathrm{~cm}$, respectively (see Support Protocol 3)

Chloroform

$2 \%, 4 \%, 6 \%$, and $8 \%(\mathrm{v} / \mathrm{v})$ methanol in chloroform 
9:1 (v/v) chloroform/methanol

$80 \%(\mathrm{v} / \mathrm{v})$ aqueous acetonitrile

Acetonitrile

Triethylamine, stored over coarse granules of calcium hydride

4,4'-Dimethoxytrityl chloride

$0 \%$ to $1 \%(\mathrm{v} / \mathrm{v})$ methanol in chloroform, containing $0.25 \%(\mathrm{v} / \mathrm{v})$ pyridine

2:1 (v/v) ethyl acetate/hexane

Oven, $130^{\circ} \mathrm{C}$

500-mL and 2-L round-bottom flasks

100-mL pressure-equalizing dropping funnel

Rotary evaporator connected interchangeably to water aspirator and vacuum pump

1-L separatory funnel

Filter paper, coarse porosity and fast flow rate (e.g., Quantitative QB, Fisher)

Water-cooled reflux condenser

Heating mantle

Additional reagents and equipment for TLC and column chromatography (see Support Protocol 3)

NOTE: The pyridinium form of Dowex AG50W-X8 ion-exchange resin is made by washing the hydrogen form with several changes of $20 \%$ aqueous pyridine.

\section{Prepare tetraisobutyrylguanosine}

1. Dry guanosine hydrate to constant weight in an oven at $130^{\circ} \mathrm{C}$.

A couple of hours drying is sufficient to drive off the water of crystallization.

2. Add $28.3 \mathrm{~g}(100 \mathrm{mmol})$ dry guanosine to $1 \mathrm{~L}$ anhydrous pyridine in a 2-L round-bottom flask while stirring. Fit flask with a 100-mL pressure-equalizing dropping funnel.

The guanosine will form a suspension in the pyridine.

3. Cool mixture to $0^{\circ} \mathrm{C}$ in an ice bath and use the dropping funnel to add $100 \mathrm{~mL}$ isobutyryl chloride dropwise over a 10 -min period with vigorous stirring at $0^{\circ} \mathrm{C}$. Stir $2 \mathrm{hr}$ at $0^{\circ} \mathrm{C}$.

4. Use the dropping funnel to add $100 \mathrm{~mL}$ water dropwise to the stirring solution, slowly enough that the temperature is maintained $<5^{\circ} \mathrm{C}$. Allow mixture to stand overnight at $0^{\circ} \mathrm{C}$.

5. Evaporate reaction mixture to $\sim 200 \mathrm{~mL}$ using a rotary evaporator connected to a vacuum pump.

6. Transfer slurry to a 4-L Erlenmeyer flask using $500 \mathrm{~mL}$ ethyl acetate. Stir vigorously while slowly adding $2 \mathrm{~L}$ of $1 \mathrm{M} \mathrm{NaHCO}_{3}$. Stir overnight at room temperature.

CAUTION: The mixture froths violently as carbon dioxide is evolved.

7. Transfer mixture in portions to a 1-L separatory funnel, removing the water layer at each transfer until only the ethyl acetate layer remains in the funnel. Extract three times with $300 \mathrm{~mL}$ of $1 \mathrm{M} \mathrm{NaHCO}_{3}$ and three times with $300 \mathrm{~mL}$ of $2 \mathrm{M} \mathrm{NaCl}$.

2'-OH-Protecting Groups That Are Photochemically Labile or Sensitive to Fluoride Ions

8. Dry ethyl acetate solution over $10 \mathrm{~g}$ anhydrous sodium sulfate, filter through filter paper to remove salt, and rotary evaporate filtrate using a water aspirator to a foam consisting of tetraisobutyrylguanosine. 
If desired, this intermediate can be stored at $-20^{\circ} \mathrm{C}$ in a sealed dry container (stable for many months).

\section{Prepare $N^{2}$-isobutyrylguanosine}

9. Add $11.3 \mathrm{~g}(20 \mathrm{mmol})$ tetraisobutyrylguanosine to $165 \mathrm{~mL}$ ethanol and stir to dissolve completely. $\mathrm{Cool}$ solution to $0^{\circ} \mathrm{C}$ in an ice bath.

10. Add $165 \mathrm{~mL}$ ice-cold $2 \mathrm{~N} \mathrm{NaOH}$ to mixture while stirring at $0^{\circ} \mathrm{C}$. Stir $5 \mathrm{~min}$, then warm mixture quickly to room temperature and let stand $10 \mathrm{~min}$.

The timing of this step is critical.

11. Immediately pour solution into a 1.5 -L beaker that contains $450 \mathrm{~mL}$ Dowex AG50W$\mathrm{X} 8$ ion-exchange resin (pyridinium form) while stirring.

The $\mathrm{pH}$ should now be near neutral.

12. Pour contents of the beaker into a $5 \times 60-\mathrm{cm}$ glass chromatography column filled with $50 \mathrm{~mL}$ Dowex AG50W-X8 ion-exchange resin (pyridinium form) and wash column with $3 \mathrm{~L}$ water, collecting eluate.

13. Using the rotary evaporator connected to water aspirator, evaporate eluate to dryness, co-evaporate twice with $100 \mathrm{~mL}$ water, and then crystallize the residue from water.

14. Examine reaction mixture by TLC (see Support Protocol 3) in 4:1 chloroform/methanol.

An $80 \%$ to $90 \%$ yield (based on the starting quantity of guanosine) of $\mathrm{N}^{2}$-isobutyrylguanosine is expected. A band with an $R_{f}$ of 0.4 should be visible following TLC.

15. Dry the $N^{2}$-isobutyrylguanosine in a vacuum desiccator over phosphorus pentoxide before use.

If desired, this intermediate can be stored at $-20^{\circ} \mathrm{C}$ in a sealed dry container (stable for many months).

\section{Prepare 2',3'-O-dibutylstannylene- $\mathrm{N}^{2}$-isobutyrylguanosine}

16. Add $5.3 \mathrm{~g}(15 \mathrm{mmol})$ dry $N^{2}$-isobutyrylguanosine and $3.75 \mathrm{~g}(15 \mathrm{mmol})$ dibutyltin oxide to $750 \mathrm{~mL}$ methanol in a $2-\mathrm{L}$ round-bottom flask while stirring.

17. Attach a water-cooled reflux condenser, heat to boiling with a heating mantle, reflux mixture $45 \mathrm{~min}$, and allow to cool.

18. Rotary evaporate resulting clear solution using a water aspirator to remove methanol, then dry the white solid, $2^{\prime}, 3^{\prime}$-O-dibutylstannylene- $N^{2}$-isobutyrylguano-sine, in a vacuum desiccator over phosphorus pentoxide.

A yield of $8 \mathrm{~g}$ is expected.

If desired, this intermediate can be stored at $-20^{\circ} \mathrm{C}$ in a sealed dry container (stable for many months).

\section{Prepare 2'-O-(2-nitrobenzyloxymethyl)- $\mathrm{N}^{2}$-isobutyrylguanosine}

19. Add $6.51 \mathrm{~g}$ (11.2 mmol) $2^{\prime}, 3^{\prime}$-O-dibutylstannylene- $N^{2}$-isobutyrylguanosine to 100 $\mathrm{mL}$ anhydrous dimethylformamide in a $500-\mathrm{mL}$ round-bottom flask, while stirring to dissolve. Heat mixture to $60^{\circ} \mathrm{C}$ with a heating mantle.

20. Add freshly prepared 2-nitrobenzyl chloromethyl ether (from $16 \mathrm{mmol}$ 2-nitrobenzyl methylthiomethyl ether as described; see Support Protocol 1) dropwise over a 5-min period while stirring at $60^{\circ} \mathrm{C}$. Seal flask and stir $2 \mathrm{hr}$ at room temperature.

Protection of Nucleosides for Oligonucleotide Synthesis

\subsubsection{7}

Supplement 3 
21. Add $5 \mathrm{~mL}$ anhydrous pyridine, followed by $2 \mathrm{~mL}$ water while stirring. Stir $20 \mathrm{~min}$ at room temperature.

22. Concentrate mixture using the rotary evaporator connected to a vacuum pump to remove as much dimethylformamide as possible.

If desired, this intermediate can be stored at $-20^{\circ} \mathrm{C}$ in a sealed dry container (stable for many months).

\section{Purify 2'-O-(2-nitrobenzyloxymethyl)- $N^{2}$-isobutyrylguanosine}

23. Dissolve residue in a minimum volume of anhydrous pyridine and, using a Pasteur pipet, transfer it dropwise onto $10 \mathrm{~g}$ silica gel 60 in a large petri plate. Allow wet silica to dry in the moving airstream inside a fume hood.

An overnight drying time should be adequate if most of the dimethylformamide was removed and the minimum amount of pyridine was used.

24. Pulverize the dry, coated, crusty silica. Layer powder onto a $2.5 \times 25-\mathrm{cm}$ glass chromatography column and elute with $100 \mathrm{~mL}$ chloroform, followed by $200 \mathrm{~mL}$ of $2 \%$ methanol in chloroform, $200 \mathrm{~mL}$ of $4 \%$ methanol in chloroform, and 6\% methanol in chloroform until all product is off the column (see Support Protocol 3).

25. Monitor fractions by TLC in 9:1 chloroform/methanol.

26. Combine appropriate fractions and rotary evaporate to dryness using a water aspirator.

27. Repeat steps 23 to 26 , except use $2.5 \mathrm{~g}$ silica gel 60 in a $2.5 \times 30-\mathrm{cm}$ glass chromatography column and elute with $100 \mathrm{~mL}$ of $2 \%$ methanol in chloroform, 100 $\mathrm{mL}$ of $4 \%$ methanol in chloroform, $200 \mathrm{~mL}$ of $6 \%$ methanol in chloroform, then $8 \%$ methanol in chloroform.

A yield of $1.7 \mathrm{~g}\left(30 \%\right.$ of the starting quantity of $2^{\prime}, 3^{\prime}$-O-dibutylstannylene- $\mathrm{N}^{2}$-isobutyrylguanosine) is expected.

If desired, this intermediate can be stored at $-20^{\circ} \mathrm{C}$ in a sealed dry container (stable for many months).

28. Dissolve dry $2^{\prime}-O$-(2-nitrobenzyloxymethyl)- $N^{2}$-isobutyrylguanosine in a minimal amount of $80 \%$ aqueous acetonitrile with heating.

29. Using the rotary evaporator connected to a water aspirator, co-evaporate several times with acetonitrile to a volume of $\sim 5 \mathrm{~mL}$ until crystallization of the desired 2 '-isomer occurs.

Additional crops may be obtained that require recrystallization.

The $2^{\prime}$-isomer has a melting point of $176^{\circ}$ to $177^{\circ} \mathrm{C}$.

If desired, this intermediate can be stored at $-20^{\circ} \mathrm{C}$ in a sealed dry container (stable for many months).

\section{Prepare 5'-O-(4,4'-dimethoxytrityl)-2'-O-(2-nitrobenzyloxymethyl)- $\mathrm{N}^{2}-$}

\section{isobutyrylguanosine}

30. Using the rotary evaporator connected to vacuum pump, dry $1.2 \mathrm{~g}(2.32 \mathrm{mmol})$ $2^{\prime}$-O-(2-nitrobenzyloxymethyl)- $N^{2}$-isobutyrylguanosine by two co-evaporations with $30 \mathrm{~mL}$ anhydrous pyridine.

2'-OH-Protecting Groups That Are Photochemically Labile or Sensitive to Fluoride Ions

31. Dissolve residual oil in $30 \mathrm{~mL}$ anhydrous pyridine, then add $0.39 \mathrm{~mL}(2.8 \mathrm{mmol})$ triethylamine and $0.94 \mathrm{~g}(2.8 \mathrm{mmol})$ 4,4'-dimethoxytrityl chloride. Stir $3 \mathrm{hr}$ at room temperature. 
32. Add $0.5 \mathrm{~mL}$ methanol and, after $10 \mathrm{~min}$, rotary evaporate using a vacuum pump to remove solvents.

33. Dissolve residue in $150 \mathrm{~mL}$ ethyl acetate and extract three times with $100 \mathrm{~mL}$ of 1 $\mathrm{M} \mathrm{NaHCO}_{3}$ and once with $100 \mathrm{~mL}$ of $2 \mathrm{M} \mathrm{NaCl}$.

34. Repeat step 8, using $5 \mathrm{~g}$ of anhydrous sodium sulfate.

35. Layer $\sim 1$-g portions of this material dissolved in a minimal amount of chloroform on $2.5 \times 30-\mathrm{cm}$ silica gel columns and elute with a 1 -L stepwise gradient of $0 \%$ to $1 \%$ methanol in chloroform containing $0.25 \%$ pyridine.

36. Monitor fractions by TLC in 2:1 ethyl acetate/hexane.

37. Using the rotary evaporator connected to a water aspirator, evaporate appropriate fractions to produce $5^{\prime}-O$-(4,4'-dimethoxytrityl)-2'-O-(2-nitrobenzyloxymethyl)- $N^{2}$ isobutyrylguanosine.

A yield of $1.8 \mathrm{~g}$ is expected.

38. Store the pure protected nucleoside in the dark at $-20^{\circ} \mathrm{C}$ in a sealed container containing a trace of pyridine (stable for many months).

\section{PREPARATION OF N-PROTECTED 5' $-O$-(4,4'-DIMETHOXYTRITYL)- 2'-O-(tert-BUTYLDIMETHYLSILYL) NUCLEOSIDES}

The following protocols describe the preparation of an alternative set of ribonucleoside derivatives, utilizing the tert-butyldimethylsilyl group for protection of their 2 '-hydroxyls (Figure 2.5.6). In the cases of adenosine and guanosine, the exocyclic amine functions of the nucleobases are protected by phenoxyacetyl groups; these form part of a quick deprotection strategy (see Commentary).

As an adjunct to the synthesis procedures detailed below, information regarding the properties of the tert-butyldimethylsilyl-protected nucleosides can be found in Tables 2.5.5 and 2.5.6; these data should prove useful in characterizing the title compounds and their synthetic intermediates.

CAUTION: Chromatographic solvents used in these protocols are flammable. Avoid spills and work in a well-vented fume hood away from potential ignition sources.

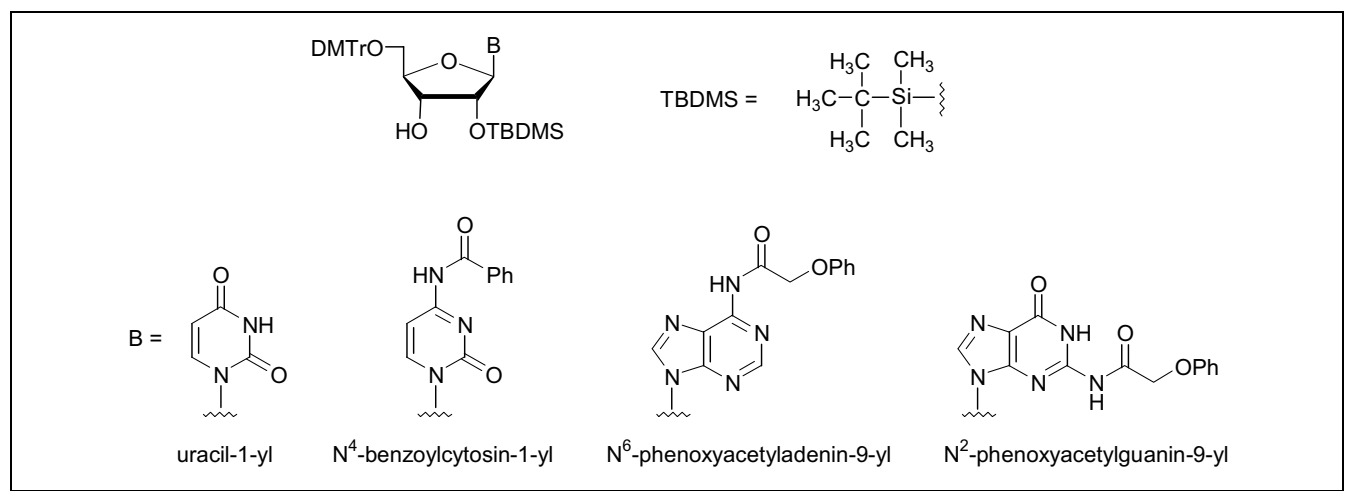

Figure 2.5.6 The four 5'-O-(4,4'-dimethoxytrityl)-2'-O-(tert-butyldimethylsilyl) ribonucleosides. The general structure of these ribonucleosides is in the upper-left corner and the four bases $(B)$ are shown below. DMTr is the 4,4'-dimethoxytrityl group (Fig. 2.5.1), and TBDMS is the tert-butyldimethylsilyl group.

Protection of Nucleosides for Oligonucleotide Synthesis

2.5.19

Supplement 3 
ALTERNATE PROTOCOL 1

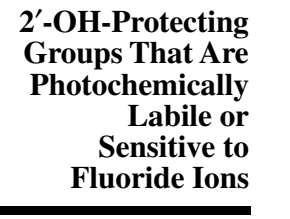

Table 2.5.5 $R_{\mathrm{f}}$ Values of tert-Butyldimethylsilyl-Protected Ribonucleosides and Their Precursors on Merck Silica Gel $60 \mathrm{~F}_{254}$ TLC Plates $^{a}$

\begin{tabular}{|c|c|c|}
\hline Ribonucleoside $^{b}$ & $R_{\mathrm{f}}$ value & Solvent system \\
\hline $\mathrm{A}^{\mathrm{Pa}}$ & 0.60 & $4: 1$ methylene chloride/methanol \\
\hline $\mathrm{G}^{\mathrm{Pa}}$ & 0.32 & 4:1 methylene chloride/methanol \\
\hline $5^{\prime} \mathrm{DMTrU}$ & 0.28 & $9: 1$ chloroform/methanol \\
\hline $5^{\prime} \mathrm{DMTrC}{ }^{\mathrm{Bz}}$ & 0.30 & 9:1 chloroform/methanol \\
\hline $5^{\prime} \mathrm{DMTrA}^{\mathrm{Pa}}$ & 0.82 & 9:1 methylene chloride/methanol \\
\hline $5^{\prime} \mathrm{DMTrG}{ }^{\mathrm{Pa}}$ & 0.55 & 9:1 methylene chloride/methanol \\
\hline 5'DMTrU2'TBDMS & 0.22 & 3:1 diethyl ether/hexane \\
\hline 5'DMTrC ${ }^{\mathrm{Bz}} 2^{\prime} \mathrm{TBDMS}$ & 0.77 & 19:1 chloroform/methanol \\
\hline 5'DMTrA ${ }^{\mathrm{Pa}} 2^{\prime} \mathrm{TBDMS}$ & 0.82 & 1:1 methylene chloride/ethyl acetate \\
\hline 5'DMTrG ${ }^{\mathrm{Pa}} 2^{\prime} \mathrm{TBDMS}$ & 0.45 & 1:1 methylene chloride/ethyl acetate \\
\hline
\end{tabular}

${ }^{a}$ Data are from Hakimelahi et al. (1982) and Chaix et al. (1989).

${ }^{b}$ Abbreviations: A, adenosine; C, cytidine; G, guanosine; U, uridine; Bz, benzoyl; DMTr, 4,4'-dimethoxytrityl; Pa, phenoxyacetyl; TBDMS, tert-butyldimethylsilyl.

CAUTION: Use fresh diethyl ether when removal of this solvent by evaporation is required, otherwise explosive peroxides may develop.

NOTE: Excellent chromatographic separations are obtained using the fine grade of silica gel recommended in Alternate Protocols 1 through 4. However, with small column diameters, solvents must be pushed through the silica by the application of external pressure, so flash chromatography columns are required. In other respects, the separation methods are based on information provided in Hakimelahi et al. (1982), Chaix et al. (1989), and Sinha et al. (1993).

\section{Synthesis of $5^{\prime}-O-\left(4,4^{\prime}\right.$-Dimethoxytrityl)-2' $-O$-(tert-butyldimethylsilyl)uridine}

In this protocol, uridine is converted into its $5^{\prime}-O$ - $\left(4,4^{\prime}\right.$-dimethoxytrityl $)$ derivative, which, upon reaction with tert-butyldimethylsilyl chloride in the presence of silver nitrate as catalyst, forms predominantly the desired 2'-O-(tert-butyldimethylsilyl) isomer. The reaction scheme is shown in Figure 2.5.7.

Table 2.5.6 ${ }^{1} \mathrm{H}$-NMR Chemical Shifts ${ }^{a}$ of tert-Butyldimethylsilyl-Protected Purine Ribonucleosides and Their Synthetic Intermediates ${ }^{b}$

\begin{tabular}{|c|c|c|c|c|c|c|}
\hline Hydrogen & $\mathrm{A}^{\mathrm{Pa}}$ & $\mathrm{G}^{\mathrm{Pa}}$ & $5^{\prime} \mathrm{DMTr} \mathrm{A}^{\mathrm{Pa}}$ & $5^{\prime} \mathrm{DMTrG}{ }^{\mathrm{Pa}}$ & $\begin{array}{l}5^{\prime} \mathrm{DMTrA}^{\mathrm{Pa}} 2^{\prime} \\
\text { TBDMS }\end{array}$ & $\begin{array}{l}5^{\prime} \mathrm{DMTrG}^{\mathrm{Pa}} 2^{\prime} \\
\text { TBDMS }\end{array}$ \\
\hline $\mathrm{H} 1^{\prime}$ & 6.21 & 6.01 & 6.27 & 6.05 & 6.27 & 6.06 \\
\hline $\mathrm{H} 2^{\prime}$ & 4.98 & 4.78 & 5.12 & 4.87 & 5.24 & 4.93 \\
\hline H3' & 4.55 & 4.54 & 4.76 & 4.59 & 4.64 & 4.52 \\
\hline $\mathrm{H} 4^{\prime}$ & 4.30 & 4.22 & 4.39 & 4.33 & 4.40 & 4.34 \\
\hline $\mathrm{H} 5^{\prime \prime}$ & 3.92 & 3.91 & 3.54 & 3.51 & 3.58 & 3.57 \\
\hline $\mathrm{H} 5^{\prime}$ & 3.92 & 3.91 & 3.54 & 3.51 & 3.57 & 3.52 \\
\hline $\mathrm{H} 2$ & 8.70 & NA & 8.70 & NA & 8.71 & NA \\
\hline H8 & 8.76 & 8.27 & 8.61 & 8.12 & 8.62 & 8.18 \\
\hline
\end{tabular}

${ }^{a}$ The internal reference for ${ }^{1} \mathrm{H}-\mathrm{NMR}$ spectra was tetramethylsilane at $0 \mathrm{ppm}$. The solvent was acetone- $d_{6}$. All shifts are measured in ppm. These data, from Chaix et al. (1989), are useful and commonly observed resonances.

${ }^{b}$ Abbreviations: A, adenosine; G, guanosine; DMTr, 4,4'-dimethoxytrityl; Pa, phenoxyacetyl; TBDMS, tert-butyldimethylsilyl; NA, not applicable. 


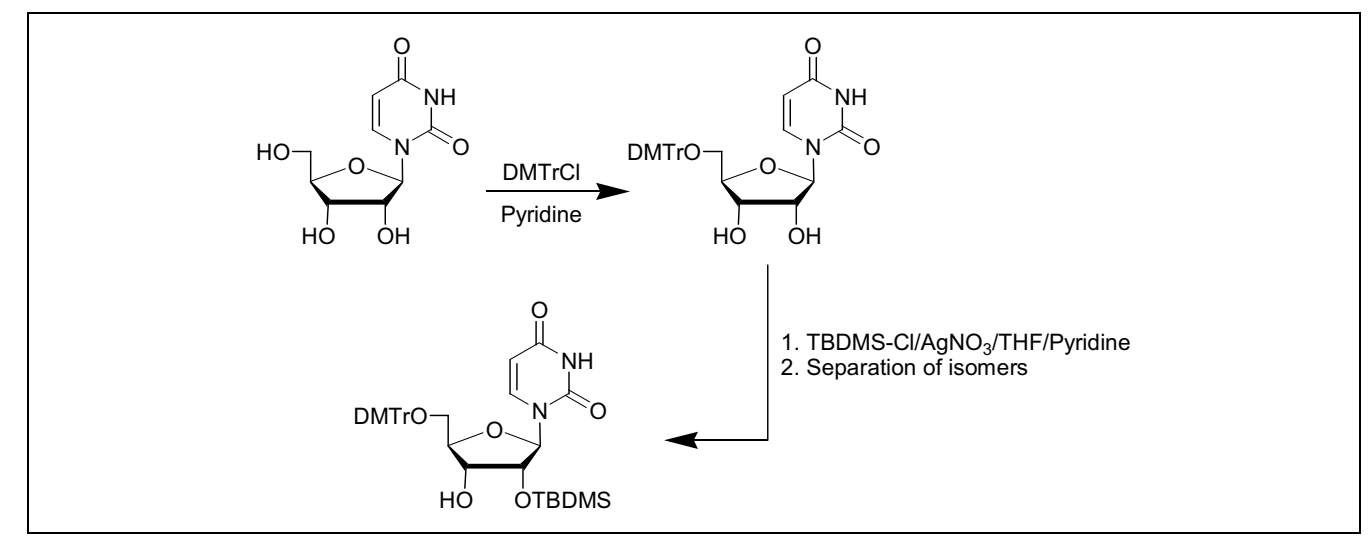

Figure 2.5.7 Preparation of $5^{\prime}-O-\left(4,4^{\prime}\right.$-dimethoxytrityl)-2'-O-(tert-butyldimethylsilyl)uridine from uridine.

\section{Materials}

Uridine

Anhydrous pyridine, stored over coarse granules of calcium hydride

4,4'-Dimethoxytrityl chloride

Methanol

Methylene chloride

$1 \mathrm{M} \mathrm{NaHCO}_{3}$

Anhydrous sodium sulfate

$1: 20(\mathrm{v} / \mathrm{v})$ chloroform/hexane

$3 \times 30-\mathrm{cm}$ and $3 \times 60-\mathrm{cm}$ flash chromatography columns (with reservoirs and

flow controller), packed with silica gel 60, 230 to 400 Mesh ASTM (see

Support Protocol 3)

Diethyl ether containing $0.25 \%$ (v/v) pyridine

Ethyl acetate containing $0.25 \%(\mathrm{v} / \mathrm{v})$ pyridine

9:1 (v/v) chloroform/methanol

Anhydrous tetrahydrofuran

Silver nitrate

tert-Butyldimethylsilyl chloride

$3: 1(\mathrm{v} / \mathrm{v})$ diethyl ether/hexane

$2 \mathrm{M} \mathrm{NaCl}$

Diethyl ether

$30 \%(\mathrm{v} / \mathrm{v})$ ethyl acetate in hexane

100- and 250-mL round-bottom flasks

Rotary evaporator connected interchangeably to water aspirator and vacuum pump 250-mL separatory funnels

Filter paper, coarse porosity and fast flow rate (e.g., Quantitative Q8, Fisher)

Additional reagents and equipment for TLC and column chromatography (see Support Protocol 3)

\section{Prepare 5'-O-(4,4'-dimethoxytrityl)uridine}

1. Add $2.44 \mathrm{~g}(10 \mathrm{mmol})$ uridine to $20 \mathrm{~mL}$ anhydrous pyridine in a $250-\mathrm{mL}$ round-bottom flask, while stirring to dissolve. Seal flask and cool solution in an ice bath. 
2. Add $0.5 \mathrm{~g}(1.5 \mathrm{mmol}) 4,4^{\prime}$-dimethoxytrityl chloride and reseal flask. Stir at $0^{\circ} \mathrm{C}$. Each hour thereafter for $7 \mathrm{hr}$, add $0.5 \mathrm{~g}$ more $4,4^{\prime}$-dimethoxytrityl chloride, for a total of 4 $\mathrm{g}(\sim 12 \mathrm{mmol})$. Stir an additional $3 \mathrm{hr}$ at $0^{\circ} \mathrm{C}$.

3. Add $3 \mathrm{~mL}$ methanol and, after $10 \mathrm{~min}$, concentrate mixture to a small volume using a rotary evaporator connected to a vacuum pump.

If desired, this intermediate can be stored at $-20^{\circ} \mathrm{C}$ in a sealed, dry container (stable for many months).

4. Add $50 \mathrm{~mL}$ methylene chloride and stir. Slowly add $50 \mathrm{~mL}$ of $1 \mathrm{M} \mathrm{NaHCO}_{3}$ and stir until evolution of carbon dioxide ceases.

CAUTION: Carbon dioxide is evolved.

5. Transfer layers to a $250-\mathrm{mL}$ separatory funnel with $50 \mathrm{~mL}$ methylene chloride and run off the organic layer into a second funnel. Wash organic layer with $50 \mathrm{~mL}$ water, dry it over $5 \mathrm{~g}$ anhydrous sodium sulfate, filter through filter paper to remove salt, and rotary evaporate filtrate to a thick oil using a water aspirator.

6. Triturate oil with $10 \mathrm{~mL}$ of 1:20 chloroform/hexane to remove most of the residual pyridine. Decant the wash.

\section{Purify $5^{\prime}$-O-(4,4'-dimethoxytrityl)uridine}

7. Apply residue to a $3 \times 60-\mathrm{cm}$ silica gel flash chromatography column packed in diethyl ether. Wash with $300 \mathrm{~mL}$ diethyl ether containing $0.25 \%$ pyridine, elute with ethyl acetate containing $0.25 \%$ pyridine at a rate of $3 \mathrm{~mL} / \mathrm{min}$, and collect $15-\mathrm{mL}$ fractions as described (see Support Protocol 3).

CAUTION: Diethyl ether is a highly flammable solvent that should be handled with extreme care.

8. Assay fractions by TLC (see Support Protocol 3) using 9:1 chloroform/methanol.

$$
\text { 5'-O-(4,4'-Dimethoxytrityl)uridine has an } R_{f} \text { of } 0.28 \text { (Table 2.5.5). }
$$

9. Pool appropriate fractions, rotary evaporate to dryness using a water aspirator, and crystallize the residue $(\sim 4.5 \mathrm{~g})$ from diethyl ether.

$5^{\prime}$-O-(4,4'-Dimethoxytrityl)uridine has a melting point of $111^{\circ}$ to $112^{\circ} \mathrm{C}$.

If desired, this intermediate can be stored at $-20^{\circ} \mathrm{C}$ in a sealed, dry container (stable for many months).

\section{Prepare 5'-O-(4,4'-dimethoxytrityl)-2'-O-(tert-butyldimethylsilyl)uridine}

10. Using the rotary evaporator connected to vacuum pump, dry $2.73 \mathrm{~g}(5 \mathrm{mmol})$ $5^{\prime}$-O-(4,4'-dimethoxytrityl)uridine by two co-evaporations with $25 \mathrm{~mL}$ anhydrous pyridine in a $100-\mathrm{mL}$ round-bottom flask.

11. Dissolve residue in $50 \mathrm{~mL}$ anhydrous tetrahydrofuran, then add $1.5 \mathrm{~mL}(18.5 \mathrm{mmol})$ anhydrous pyridine and $1 \mathrm{~g}(6 \mathrm{mmol})$ silver nitrate. Stir until silver nitrate dissolves $(\sim 5 \mathrm{~min})$.

12. Add $1 \mathrm{~g}(6.6 \mathrm{mmol})$ tert-butyldimethylsilyl chloride and stir $5 \mathrm{hr}$ at room temperature.

13. Examine reaction mixture by TLC in 3:1 diethyl ether/hexane.

2'-OH-Protecting Groups That Are Photochemically Labile or Sensitive to Fluoride Ions
The 2 -isomer has an $R_{f}$ of 0.22 and should be visible as the major product, running ahead of the $3^{\prime}$-isomer. 
14. Filter reaction mixture through filter paper into $50 \mathrm{~mL}$ of $1 \mathrm{M} \mathrm{NaHCO}_{3}$, then extract with $300 \mathrm{~mL}$ methylene chloride. Extract organic layer with $100 \mathrm{~mL}$ of $2 \mathrm{M} \mathrm{NaCl}$.

15. Dry organic layer over $10 \mathrm{~g}$ anhydrous sodium sulfate, filter through filter paper to remove salt, and rotary evaporate filtrate to an oil using a water aspirator.

16. Dissolve residue in $50 \mathrm{~mL}$ diethyl ether, filter to remove undissolved material, then remove solvent by rotary evaporation using a water aspirator without heating.

17. Layer mixture on a $3 \times 30-\mathrm{cm}$ silica gel flash chromatography column packed in hexane, elute using $30 \%$ ethyl acetate in hexane, and collect fractions as described.

Some experimentation may be required to determine the precise mixture or gradient of ethyl acetate in hexane that gives optimum separation of isomers.

18. Monitor fractions by TLC using 3:1 diethyl ether/hexane and rotary evaporate fractions containing the $2^{\prime}$-isomer using a water aspirator to produce the pure product, 5'-O-(4,4'-dimethoxytrityl)-2'-O-(tert-butyldimethylsilyl)uridine.

A yield of $\sim 2.3 \mathrm{~g}$, or $70 \%$ based on the starting quantity of 5'-O-(4,4'-dimethoxytrityl)uridine, is expected.

The product can be stored at $-20^{\circ} \mathrm{C}$ in a sealed, dry container (stable for many months).

\section{Synthesis of $5^{\prime}-O$-(4,4'-Dimethoxytrityl)-2'-O-(tert-butyldimethylsilyl)- $N^{4}$-benzoyl- cytidine}

In this protocol, cytidine is selectively benzoylated at its N4 position, then dimethoxytritylated to protect its $5^{\prime}$-hydroxyl. Subsequent reaction with tert-butyldimethylsilyl chloride in the presence of silver nitrate gives predominantly the $2^{\prime}-O$-(tert-butyldimethylsilyl) derivative. The reaction sequence is illustrated in Figure 2.5.8.

\section{Additional Materials (also see Alternate Protocol 1)}

Cytidine

Benzoic anhydride

Chloroform

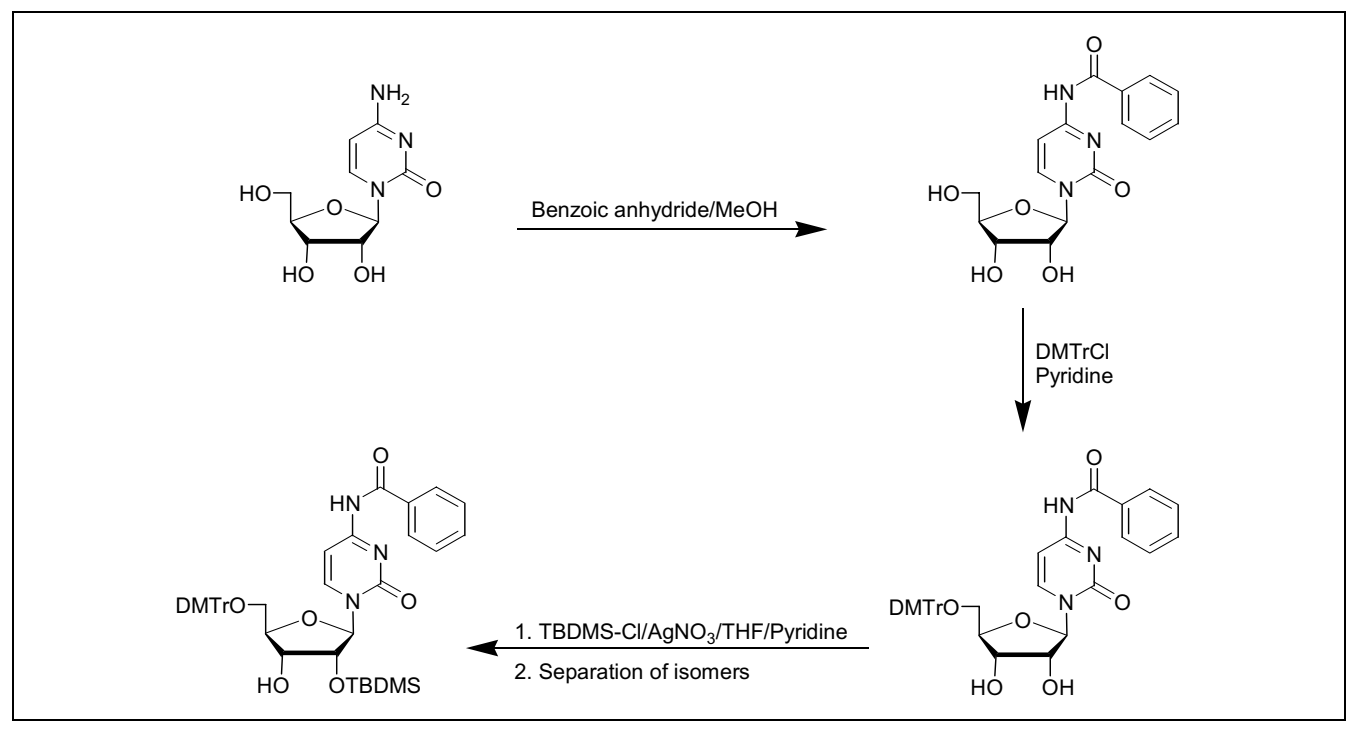

Figure 2.5.8 Preparation of $5^{\prime}-O-\left(4,4^{\prime}\right.$-dimethoxytrityl)-2'-O-(tert-butyldimethylsilyl)- $N^{4}$-benzoylcytidine from cytidine. 
19:1 (v/v) chloroform/methanol

1-L round-bottom flasks

Water-cooled reflux condenser

Heating mantle

Coarse sintered funnel

\section{Prepare $N^{4}$-benzoylcytidine}

1. Add $5 \mathrm{~g}$ (20.6 mmol) cytidine and $5 \mathrm{~g}(22.3 \mathrm{mmol})$ benzoic anhydride to $500 \mathrm{~mL}$ methanol in a 1-L round-bottom flask, while stirring. Fit flask with a water-cooled reflux condenser and heat mixture to a boil using a heating mantle.

2. At the end of each hour for the first $3 \mathrm{hr}$, briefly cool mixture and add an additional $5 \mathrm{~g}$ benzoic anhydride. Reflux for a total of $5 \mathrm{hr}$. Let mixture cool to $0^{\circ} \mathrm{C}$.

3. Collect crystals of $N^{4}$-benzoylcytidine by filtration through a coarse sintered funnel. Wash with $25 \mathrm{~mL}$ ice-cold methanol, then with diethyl ether to remove residual benzoic acid.

A yield of $4.5 \mathrm{~g}$ product (with a melting point of $218^{\circ}$ to $219^{\circ} \mathrm{C}$ ) is expected.

If desired, this intermediate can be stored at $-20^{\circ} \mathrm{C}$ in a sealed, dry container (stable for many months).

\section{Prepare 5'-O-(4,4'-dimethoxytrityl)- $N^{4}$-benzoylcytidine}

4. Using a rotary evaporator connected to a vacuum pump, dry $3.5 \mathrm{~g}(10 \mathrm{mmol})$ $N^{4}$-benzoylcytidine by two co-evaporations with $20 \mathrm{~mL}$ anhydrous pyridine.

5. Dissolve residue in $20 \mathrm{~mL}$ anhydrous pyridine in a $100-\mathrm{mL}$ round-bottom flask while stirring. Seal flask and cool solution in an ice bath to $0^{\circ} \mathrm{C}$.

6. Continue with dimethoxytritylation (see Alternate Protocol 1, steps 2 to 6), with the following exceptions:

a. Increase methanol to $5 \mathrm{~mL}$ in step 3 .

b. Decrease methylene chloride and $1 \mathrm{M} \mathrm{NaHCO}_{3}$ to $25 \mathrm{~mL}$ in step 4 .

c. Wash organic layer with $50 \mathrm{~mL}$ of $2 \mathrm{M} \mathrm{NaCl}$ instead of water in step 5 .

d. Increase 1:20 chloroform/hexane to $50 \mathrm{~mL}$ in step 6 .

7. Dissolve residue in $15 \mathrm{~mL}$ chloroform and apply to a $3 \times 60-\mathrm{cm}$ silica gel flash chromatography column packed in chloroform. Wash column with $100 \mathrm{~mL}$ chloroform and elute with 9:1 chloroform/methanol as described (see Support Protocol 3).

8. Assay fractions by TLC (see Support Protocol 3) in 9:1 chloroform/methanol. Combine fractions containing pure $5^{\prime}-O$-(4, $4^{\prime}$-dimethoxytrityl)- $N^{4}$-benzoylcytidine and rotary evaporate to dryness using a water aspirator.

This product can be crystallized (see Alternative Protocol 1, step 9), but this is probably not required.

A yield of $\sim 5.5 \mathrm{~g}$ product (with a melting point of $109^{\circ}$ to $111^{\circ} \mathrm{C}$ ) is expected.

If desired, this intermediate can be stored at $-20^{\circ} \mathrm{C}$ in a sealed, dry container (stable for many months).

2'-OH-Protecting Groups That Are Photochemically

Labile or Sensitive to Fluoride Ions 
Prepare 5'-O-(4,4'-dimethoxytrityl)-2'-O-(tert-butyldimethylsilyl)- $N^{4}$-benzoylcytidine

9. Prepare the $2^{\prime}$-O-tert-butyldimethylsilyl isomer as described (see Alternate Protocol

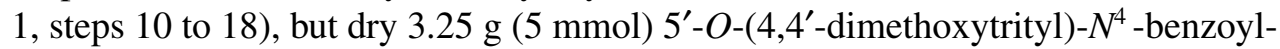
cytidine in step 10, and use 19:1 chloroform/methanol for TLC in steps 13 and 18.

A yield of $2.5 \mathrm{~g}$ is expected.

\section{Synthesis of $5^{\prime}-O-\left(4,4^{\prime}\right.$-Dimethoxytrityl)-2' $-O$-(tert-butyldimethylsilyl)- $N^{6}$-phenoxy- acetyladenosine}

In this protocol, the exocyclic amine at the N6 position of adenosine is protected as a phenoxyacetyl amide, then a dimethoxytrityl group is added to the $5^{\prime}$-hydroxyl. Treatment with tert-butyldimethylsilyl chloride and imidazole produces a mixture of the $2{ }^{\prime}$ - and 3'-O-tert-butyldimethylsilyl derivatives, which are separated by column chromatography. The reaction sequence is shown in Figure 2.5.9.

\section{Materials}

Adenosine

Anhydrous pyridine, stored over coarse granules of calcium hydride

Trimethylchlorosilane

1-Hydroxybenzotriazole

Anhydrous acetonitrile

Phenoxyacetyl chloride

Concentrated ammonium hydroxide

Chloroform

$90 \%(\mathrm{v} / \mathrm{v})$ ethanol

4,4'-Dimethoxytrityl chloride

9:1 (v/v) methylene chloride/methanol

Methanol

Ethyl acetate

$1 \mathrm{M} \mathrm{NaHCO}_{3}, 5^{\circ} \mathrm{C}$

$2 \mathrm{M} \mathrm{NaCl}$

Anhydrous sodium sulfate

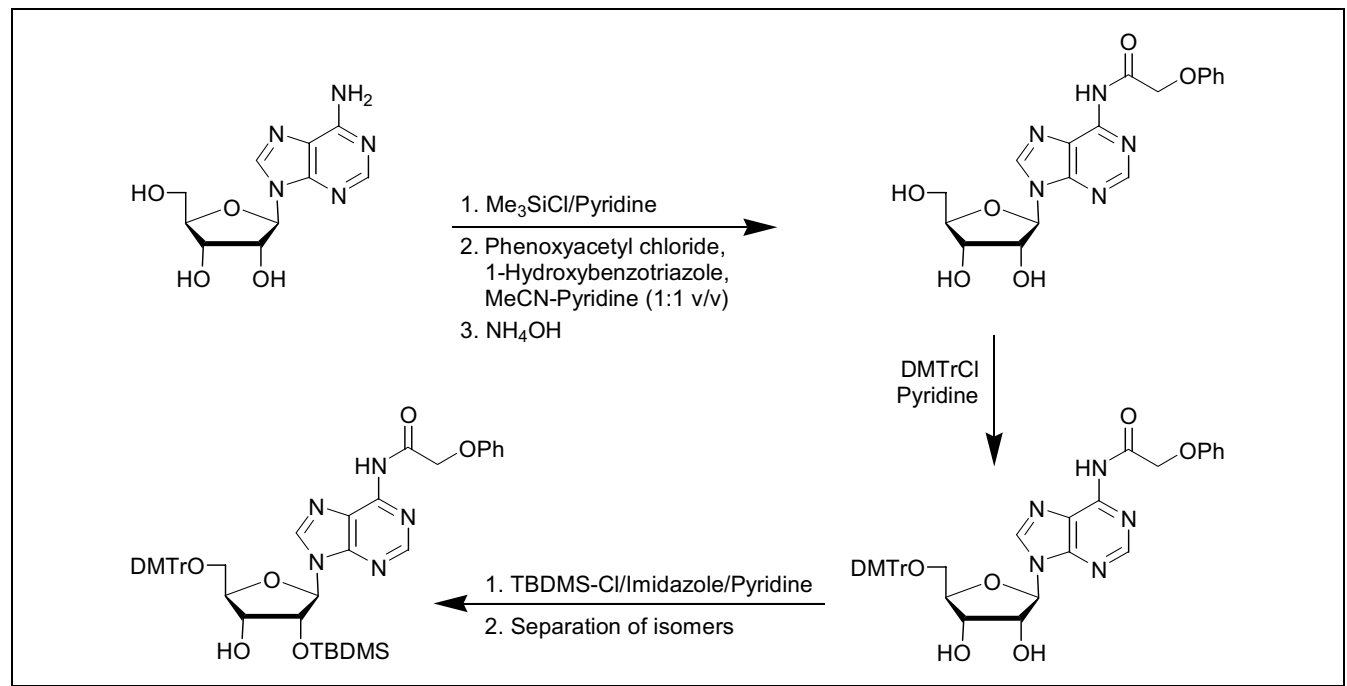

Figure 2.5.9 Preparation of $5^{\prime}-O-\left(4,4^{\prime}\right.$-dimethoxytrityl)-2'-O-(tert-butyldimethylsilyl)- $N^{6}$-phenoxyacetyladenosine from adenosine.

Protection of Nucleosides for Oligonucleotide Synthesis

2.5.25

Supplement 3 
$3 \times 30-\mathrm{cm}$ and $3 \times 60-\mathrm{cm}$ flash chromatography columns (with reservoirs and

flow controller), packed with silica gel 60, 230 to 400 Mesh ASTM (see

Support Protocol 3)

$2 \%$ to $10 \%(\mathrm{v} / \mathrm{v})$ ethanol in ethyl acetate

Imidazole

tert-Butyldimethylsilyl chloride

$1: 1(\mathrm{v} / \mathrm{v})$ methylene chloride/ethyl acetate

$1 \%$ and $35 \%(\mathrm{v} / \mathrm{v})$ ethyl acetate in hexane

Rotary evaporator connected interchangeably to water aspirator and vacuum pump 250 -mL round-bottom flasks with rubber septa

5- and 50-mL syringes and vent needles

$100-\mathrm{mL}$ pressure-equalizing dropping funnel

500-mL separatory funnel

Filter paper, coarse porosity and fast flow rate (e.g., Quantitative Q8, Fisher)

Additional reagents and materials for TLC and column chromatography (see Support Protocol 3)

\section{Prepare $N^{6}$-phenoxyacetyladenosine}

1. Using a rotary evaporator connected to a vacuum pump, dry $5.34 \mathrm{~g}(20 \mathrm{mmol})$ adenosine by two co-evaporations with $40 \mathrm{~mL}$ anhydrous pyridine in a $250-\mathrm{mL}$ round-bottom flask.

2. Suspend residue in $100 \mathrm{~mL}$ anhydrous pyridine and add $19 \mathrm{~mL}(150 \mathrm{mmol})$ trimethylchlorosilane dropwise while stirring. Stir $25 \mathrm{~min}$ at room temperature.

3. Using the rotary evaporator connected to a water aspirator, dry $4.16 \mathrm{~g}(31.6 \mathrm{mmol})$ 1-hydroxybenzotriazole in a second 250 - $\mathrm{mL}$ round-bottom flask by three co-evaporations with $30 \mathrm{~mL}$ anhydrous acetonitrile. Add $10 \mathrm{~mL}$ anhydrous acetonitrile and 10 $\mathrm{mL}$ anhydrous pyridine and stir to suspend residue.

The formation of colored side products is prevented by the use of 1-hydroxybenzotriazole.

4. Fit flask with a rubber septum. Using a $5-\mathrm{mL}$ syringe and vent needle, add $4.2 \mathrm{~mL}$ (30 mmol) phenoxyacetyl chloride dropwise through the septum, and stir $5 \mathrm{~min}$ at room temperature.

5. Cool both flasks in an ice bath to $0^{\circ} \mathrm{C}$, then, using a 50-mL syringe and a vent needle, add the contents of the first flask (containing the adenosine) dropwise through the septum to the acylating agent in the second flask. Stir overnight at room temperature.

6. Cool flask to $5^{\circ} \mathrm{C}$ and add $20 \mathrm{~mL}$ cold water, followed by $10 \mathrm{~mL}$ concentrated ammonium hydroxide. Stir $15 \mathrm{~min}$ at $5^{\circ} \mathrm{C}$.

7. Immediately remove ammonia and solvents by rotary evaporation using a water aspirator and dissolve residual gum in $600 \mathrm{~mL}$ water. Extract aqueous solution twice with $300 \mathrm{~mL}$ chloroform, then rotary evaporate to dryness using a water aspirator.

If desired, this intermediate can be stored at $-20^{\circ} \mathrm{C}$ in a sealed, dry container (stable for many months).

8. Crystallize product from $90 \%$ ethanol.

2'-OH-Protecting Groups That Are Photochemically

Labile or Sensitive to

Fluoride Ions

2.5.26

A yield of $5.2 \mathrm{~g} N^{6}$-phenoxyacetyladenosine (or 65\% based on the starting quantity of adenosine) is expected.

If desired, this intermediate can be stored at $-20^{\circ} \mathrm{C}$ in a sealed, dry container (stable for many months). 
Prepare 5'-O-(4,4'-dimethoxytrityl)- $N^{6}$-phenoxyacetyladenosine

9. Using the rotary evaporator connected to a vacuum pump, dry $4 \mathrm{~g}(10 \mathrm{mmol}) N^{6}$-phenoxyacetyladenosine by two co-evaporations with $10 \mathrm{~mL}$ anhydrous pyridine in a $250-\mathrm{mL}$ round-bottom flask.

10. Dissolve residue in $60 \mathrm{~mL}$ anhydrous pyridine. Put a stir-bar in the flask, fit it with a 100-mL pressure-equalizing dropping funnel, and cool mixture to $5^{\circ} \mathrm{C}$.

11. Dissolve $3.73 \mathrm{~g}$ (11 mmol) 4,4'-dimethoxytrityl chloride in $40 \mathrm{~mL}$ anhydrous pyridine, then add it dropwise over a 2-hr period to the $N^{6}$-phenoxyacetyladenosine while stirring. Let stand overnight at $5^{\circ} \mathrm{C}$.

12. Examine solution by TLC (see Support Protocol 3) in 9:1 methylene chloride/methanol.

The 5'-O-(4,4'-dimethoxytrityl) derivative is the major product.

13. Add $5 \mathrm{~mL}$ methanol, stir $5 \mathrm{~min}$, then rotary evaporate reaction mixture to a slurry using a vacuum pump.

14. Using $200 \mathrm{~mL}$ ethyl acetate, transfer residue to a $500-\mathrm{mL}$ separatory funnel. Extract twice with $100 \mathrm{~mL}$ cold $\left(5^{\circ} \mathrm{C}\right) 1 \mathrm{M} \mathrm{NaHCO}_{3}$ and once with $100 \mathrm{~mL}$ of $2 \mathrm{M} \mathrm{NaCl}$.

15. Dry organic layer over $5 \mathrm{~g}$ anhydrous sodium sulfate, filter through filter paper to remove salt, and rotary evaporate filtrate to a yellow foam using a water aspirator.

If desired, this intermediate can be stored at $-20^{\circ} \mathrm{C}$ in a sealed, dry container (stable for many months).

16. Layer material on a $3 \times 60-\mathrm{cm}$ silica gel flash chromatography column packed in ethyl acetate and elute initially with ethyl acetate, then with a stepwise gradient of $2 \%$ to $10 \%$ ethanol in ethyl acetate as described (see Support Protocol 3). Use 200-mL portions of ethyl acetate, then $2 \%$ ethanol, $4 \%$ ethanol, and so on.

17. Monitor fractions by TLC using 9:1 methylene chloride/methanol and rotary evaporate appropriate fractions using a water aspirator to produce the pure product, $5^{\prime}-O$-(4,4'-dimethoxytrityl)- $N^{6}$-phenoxyacetyladenosine.

A 55\% yield is expected based on the starting quantity of $N^{6}$-phenoxyacetyladenosine.

\section{Prepare 5'-O-(4,4'-dimethoxytrityl)-2'-O-(tert-butyldimethylsilyl)- $N^{6}$-phenoxyacetyl- adenosine}

18. Using the rotary evaporator connected to a vacuum pump, dry $2.8 \mathrm{~g}(4 \mathrm{mmol})$ $5^{\prime}$ - $O$-(4,4'-dimethoxytrityl)- $N^{6}$-phenoxyacetyladenosine by two co-evaporations with $10 \mathrm{~mL}$ anhydrous pyridine. Dissolve residue in $40 \mathrm{~mL}$ anhydrous pyridine.

19. Add $0.8 \mathrm{~g}$ (11.8 mmol) imidazole, followed by $0.35 \mathrm{~g}(2.4 \mathrm{mmol})$ tert-butyldimethylsilyl chloride. Stir $24 \mathrm{hr}$ at room temperature.

20. Add another $0.35 \mathrm{~g}$ tert-butyldimethylsilyl chloride and stir $24 \mathrm{hr}$ at room temperature.

21. Repeat step 20.

22. Check reaction by TLC in 1:1 methylene chloride/ethyl acetate.

The starting material should be completely converted into its 2'-silyl, $3^{\prime}$-silyl, and 2', $3^{\prime}$-disilyl derivatives. The $2^{\prime}, 3^{\prime}$-disilyl derivative is the fastest running product, followed by the $2^{\prime}$-silyl derivative, and then the $3^{\prime}$-silyl derivative.

23. Cool mixture to $0^{\circ} \mathrm{C}$ and add $5 \mathrm{~mL}$ water.

Protection of Nucleosides for Oligonucleotide Synthesis

2.5.27 
ALTERNATE PROTOCOL 4

24. Rotary evaporate mixture to dryness using a vacuum pump, dissolve residue in 300 $\mathrm{mL}$ chloroform, and extract chloroform solution twice with $150 \mathrm{~mL}$ cold $1 \mathrm{M}$ $\mathrm{NaHCO}_{3}$ and once with $150 \mathrm{~mL}$ water. Remove chloroform by rotary evaporation using a water aspirator.

25. Layer residual mixture on a $3 \times 30-\mathrm{cm}$ silica gel flash chromatography column packed in $1 \%$ ethyl acetate in hexane and elute with $35 \%$ ethyl acetate in hexane.

Some experimentation may be required to determine the precise mixture or gradient of ethyl acetate in hexane that gives optimum separation of isomers.

26. Monitor fractions by TLC using 1:1 methylene chloride/ethyl acetate, combine fractions containing pure $2^{\prime}$-isomer, and rotary evaporate them using a water aspirator to produce the pure product, $5^{\prime}-O$-(4,4'-dimethoxytrityl)-2'-O-(tert-butyldimethylsilyl)- $N^{6}$-phenoxyacetyladenosine.

A yield of $35 \%$, based on the starting quantity of $5^{\prime}-O-\left(4,4^{\prime}\right.$-dimethoxytrityl $)-N^{6}-$ phenoxyacetyladenosine, is expected.

The product can be stored at $-20^{\circ} \mathrm{C}$ in a sealed, dry container (stable for many months).

\section{Synthesis of $5^{\prime}-O-\left(4,4^{\prime}\right.$-Dimethoxytrityl)-2'-O-(tert-butyldimethylsilyl)- $N^{2}$-phenoxy- acetylguanosine}

In this protocol, the exocyclic amine at the N2 position of guanosine is protected as a phenoxyacetyl amide, then a $4,4^{\prime}$-dimethoxytrityl group is added to the $5^{\prime}$-hydroxyl. Treatment with tert-butyldimethylsilyl chloride and imidazole gives a mixture of the 2 ' - and 3'-O-tert-butyldimethylsilyl derivatives, which are separated by column chromatography. The reaction sequence is shown in Figure 2.5.10. This protocol is performed by following steps 1 to 26 of Alternate Protocol 3, with the exceptions outlined below.

Additional Materials (also see Alternate Protocol 3)

Guanosine hydrate

$50 \%(\mathrm{v} / \mathrm{v})$ ethyl acetate in hexane

Oven, $130^{\circ} \mathrm{C}$
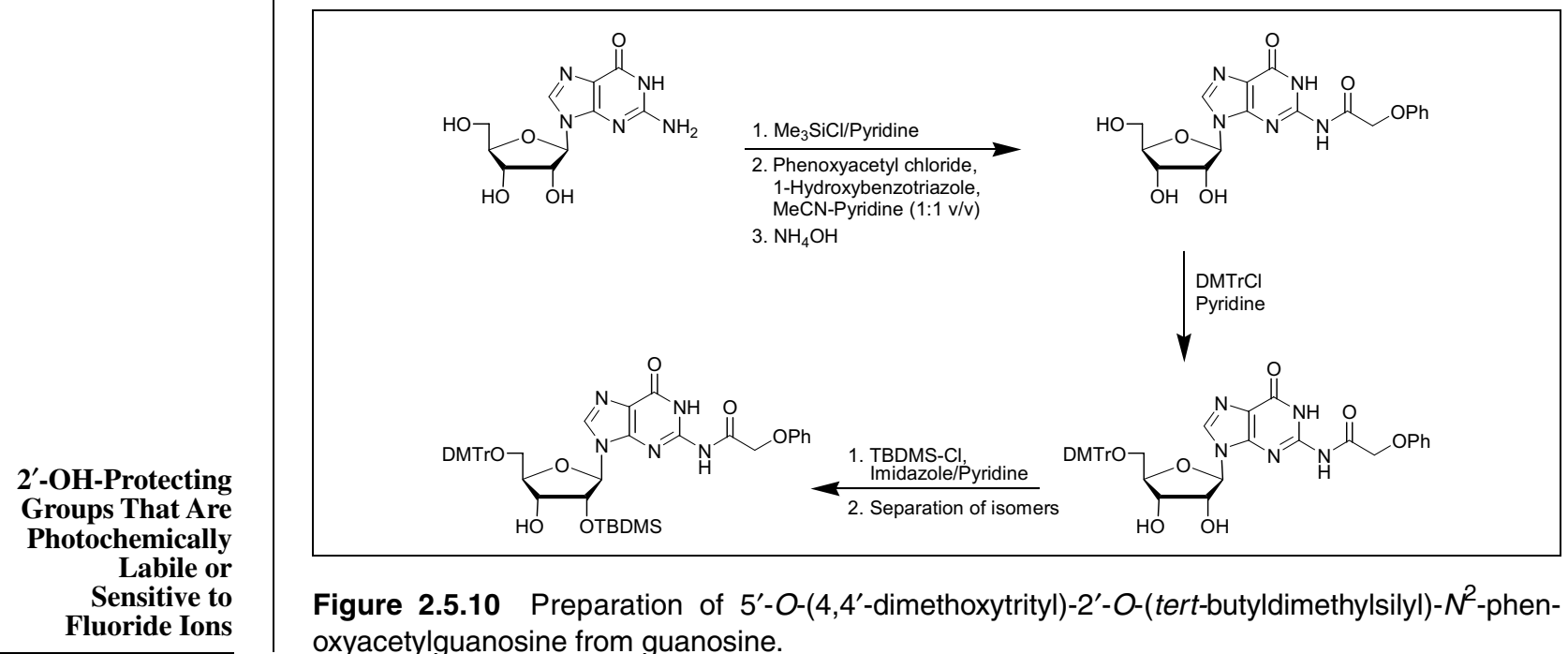

Figure 2.5.10 Preparation of $5^{\prime}-O-\left(4,4^{\prime}\right.$-dimethoxytrityl)-2'-O-(tert-butyldimethylsilyl)- $N^{2}$-phenoxyacetylguanosine from guanosine. 
1a. Dry guanosine hydrate to constant weight in an oven at $130^{\circ} \mathrm{C}$.

Dry guanosine can be stored for many months in a sealed container at room temperature.

2a. Suspend $5.66 \mathrm{~g}$ ( $20 \mathrm{mmol})$ dry guanosine in $100 \mathrm{~mL}$ anhydrous pyridine and add 19 $\mathrm{mL}(150 \mathrm{mmol})$ trimethylchlorosilane dropwise while stirring. Stir $25 \mathrm{~min}$ at room temperature.

9a. Using a rotary evaporator connected to a vacuum pump, dry $4.12 \mathrm{~g}(10 \mathrm{mmol})$ of $N^{2}$-phenoxyacetylguanosine by two co-evaporations with $10 \mathrm{~mL}$ anhydrous pyridine in a $250-\mathrm{mL}$ round-bottom flask.

18a. Using the rotary evaporator connected to a vacuum pump, dry $2.9 \mathrm{~g}(4 \mathrm{mmol})$ $5^{\prime}-O$ - $\left(4,4^{\prime}\right.$-dimethoxytrityl $)-N^{2}$-phenoxyacetylguanosine by two co-evaporations with $10 \mathrm{~mL}$ anhydrous pyridine. Dissolve residue in $40 \mathrm{~mL}$ anhydrous pyridine.

25a. Layer residual mixture on a $3 \times 30-\mathrm{cm}$ silica gel flash chromatography column packed in hexane and elute with 50\% ethyl acetate in hexane as described.

Expected yields are: $60 \% \mathrm{~N}^{2}$-phenoxyacetylguanosine, 50\% 5'-O-(4,4'-dimethoxytrityl)-

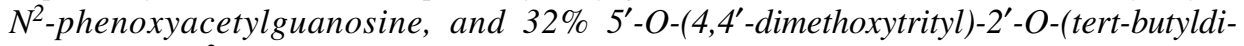
methylsilyl)- $N^{2}$-phenoxyacetylguanosine, all based on the amount of starting material.

\section{PREPARATION OF 2-NITROBENZYL CHLOROMETHYL ETHER}

2-Nitrobenzyl chloromethyl ether is the alkylating agent used to convert nucleosides to their 2'-O-(2-nitrobenzyloxymethyl) derivatives. It is moderately unstable and must be prepared fresh each time it is used. The reaction is shown in Figure 2.5.11. The precursor, 2-nitrobenzyl methylthiomethyl ether, can be synthesized in quantity and stored for many months in the dark at $-20^{\circ} \mathrm{C}$.

CAUTION: A foul-smelling aqueous layer is produced in step 7. Work in a fume hood with yellow lights.

\section{Materials}

2-Nitrobenzyl alcohol

Dimethyl sulfoxide, dried over 4A molecular sieves

Acetic anhydride

Acetic acid

1:1 (v/v) diethyl ether/hexane

Sodium bicarbonate

1:1 (v/v) ethyl acetate/hexane

Saturated sodium bicarbonate

$2 \mathrm{M} \mathrm{NaCl}$

Anhydrous sodium sulfate

$5 \times 60-\mathrm{cm}$ chromatography column packed with silica gel 60,70 to 230 mesh

ASTM, in hexane to a bed height of $56 \mathrm{~cm}$ (see Support Protocol 3)

$1 \%, 5 \%, 10 \%$, and $15 \%(\mathrm{v} / \mathrm{v})$ diethyl ether in hexane

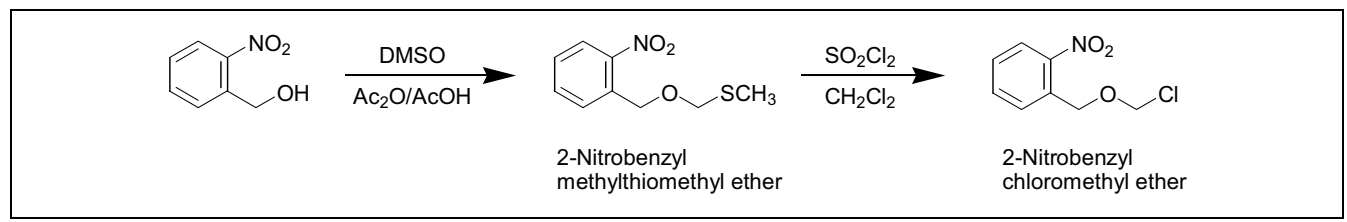

Figure 2.5.11 Preparation of 2-nitrobenzyl chloromethyl ether from 2-nitrobenzyl alcohol.

Protection of Nucleosides for Oligonucleotide Synthesis

2.5.29

Supplement 3 
Anhydrous methylene chloride

Ethanol (for dry ice/ethanol bath)

$1 \mathrm{M} \mathrm{SO}_{2} \mathrm{Cl}_{2}$ in methylene chloride

Anhydrous dimethylformamide, store over 4A molecular sieves

500-mL separatory funnel

Filter paper, coarse porosity and fast flow rate (e.g., Quantitative Q8, Fisher)

Rotary evaporator connected to water aspirator

250-mL round-bottom flask

50-mL pressure-equalizing dropping funnel

Additional reagents and equipment for TLC and column chromatography (see Support Protocol 3)

CAUTION: The sulfuryl chloride $\left(\mathrm{SO}_{2} \mathrm{Cl}_{2}\right)$ solution is corrosive and extremely toxic.

\section{Prepare 2-nitrobenzyl methylthiomethyl ether}

1. Dissolve $23 \mathrm{~g}$ ( $150 \mathrm{mmol})$ 2-nitrobenzyl alcohol in $150 \mathrm{~mL}$ dry dimethyl sulfoxide in a $1-\mathrm{L}$ flask.

2. Add $108 \mathrm{~mL}$ acetic anhydride and $77 \mathrm{~mL}$ acetic acid and stir to dissolve. Allow the homogeneous, yellow-tinted solution to stand $24 \mathrm{hr}$ at room temperature in the dark.

3. Examine the mixture by TLC (see Support Protocol 3) using 1:1 diethyl ether/hexane.

The fastest-running of the three UV-absorbing bands is the desired product.

4. Pour reaction mixture into a 500-mL separatory funnel, then add it dropwise over a 2-hr period to a vigorously stirred slurry of $330 \mathrm{~g}$ sodium bicarbonate in $1.5 \mathrm{~L}$ water. Stir $24 \mathrm{hr}$ in the dark.

The evolution of carbon dioxide is well controlled by the dropwise addition of the mixture.

5. Allow the oily product to settle to the bottom of the container, then decant the aqueous supernatant.

6. Dissolve oil in $400 \mathrm{~mL}$ of 1:1 ethyl acetate/hexane and extract this solution three times with $100 \mathrm{~mL}$ saturated sodium bicarbonate and once with $100 \mathrm{~mL}$ of $2 \mathrm{M} \mathrm{NaCl}$.

7. Dry organic layer over $10 \mathrm{~g}$ anhydrous sodium sulfate, filter through filter paper to remove salt, and remove volatile organic solvents on a rotary evaporator connected to a water aspirator.

The large volume of foul-smelling aqueous supernatant can be deodorized by treatment with household bleach before disposal.

\section{Purify 2-nitrobenzyl methylthiomethyl ether}

8. Layer yellow residue on a $5 \times 60-\mathrm{cm}$ silica gel column packed in $1 \%$ diethyl ether in hexane and elute at a rate of 5 to $10 \mathrm{~mL} / \mathrm{min}$ using a stepwise gradient consisting of $500 \mathrm{~mL}$ of $1 \%$ diethyl ether in hexane followed by $1 \mathrm{~L}$ each of $5 \%, 10 \%$, and $15 \%$ diethyl ether in hexane (see Support Protocol 3). Allow the first liter of eluate to run into a flask, then collect $250-\mathrm{mL}$ fractions until the product begins to emerge, as judged by TLC using 1:1 diethyl ether/hexane. Thereafter, collect 100-mL fractions.

2'-OH-Protecting Groups That Are Photochemically

Labile or Sensitive to Fluoride Ions
CAUTION: These solvents are flammable.

9. Assay fractions by TLC using 1:1 diethyl ether/hexane. Pool fractions containing the pure product, 2-nitrobenzyl methylthiomethyl ether. 
10. Remove volatile solvents on the rotary evaporator to afford a viscous, yellow oil.

A yield of 15 to $20 \mathrm{~g}$ is expected.

11. Store this stock reagent at $-20^{\circ} \mathrm{C}$ in a sealed container in the dark (stable for many months).

${ }^{1} H$ - and ${ }^{13}$ C-NMR data for this material can be found in Schwartz et al. (1992).

\section{Prepare 2-nitrobenzyl chloromethyl ether}

12. Dissolve $3.4 \mathrm{~g} \mathrm{(16} \mathrm{mmol)} \mathrm{2-nitrobenzyl} \mathrm{methylthiomethyl} \mathrm{ether} \mathrm{in} 30 \mathrm{~mL}$ anhydrous methylene chloride in a $250-\mathrm{mL}$ round-bottom flask and fit flask with a $50-\mathrm{mL}$ pressure-equalizing dropping funnel.

13. Cool mixture to $-78^{\circ} \mathrm{C}$ using a dry ice/ethanol bath.

14. Using the pressure-equalizing dropping funnel, add $16 \mathrm{~mL}$ of $1 \mathrm{M} \mathrm{SO}_{2} \mathrm{Cl}_{2}$ in methylene chloride dropwise over a 5-min period while stirring at $-78^{\circ} \mathrm{C}$. Continue to cool the mixture and stir $30 \mathrm{~min}$.

15. Quickly transfer flask to rotary evaporator and remove solvent and volatile products.

16. Repeat rotary evaporation three times with $20 \mathrm{~mL}$ anhydrous methylene chloride, then add $15 \mathrm{~mL}$ anhydrous dimethylformamide and use the clear solution immediately.

\section{PREPARATION OF PENTAFLUOROPHENYL BENZOATE}

Pentafluorophenyl benzoate is used to selectively protect cytidine at N4 in Basic Protocol 2.

\section{Materials}

2,3,4,5,6-Pentafluorophenol

Anhydrous dimethylformamide, store over 4A molecular sieves

Benzoic acid

1,3-Dicyclohexylcarbodiimide

Ethyl acetate

Ethanol

Phosphorus pentoxide

Filter paper, coarse porosity and fast flow rate (e.g., Quantitative Q8, Fisher)

Rotary evaporator connected interchangeably to water aspirator and vacuum pump

Coarse sintered funnel

CAUTION: Pentafluorophenol, pentafluorophenyl benzoate, and 1,3-dicyclohexylcarbodiimide are toxic irritants. Avoid skin contact.

1. Add $2.9 \mathrm{~g}$ (15.7 mmol) 2,3,4,5,6-pentafluorophenol to a flask containing $7 \mathrm{~mL}$ anhydrous dimethylformamide and stir to dissolve. Stopper flask to minimize exposure to atmospheric moisture and cool in an ice bath.

2. Add $1.92 \mathrm{~g}$ (15.7 mmol) benzoic acid, followed by $3.5 \mathrm{~g}$ (17.9 mmol) 1,3-dicyclohexylcarbodiimide. Stir $1 \mathrm{hr}$ at $0^{\circ} \mathrm{C}$.

A white suspension will be visible.

3. Warm mixture to room temperature and remove precipitate by suction filtration through filter paper.

Protection of Nucleosides for Oligonucleotide Synthesis

\subsubsection{1}

Supplement 3

SUPPORT PROTOCOL 2 
4. Evaporate filtrate to dryness using a rotary evaporator under high vacuum (i.e., with a vacuum pump) and a water-bath temperature $<40^{\circ} \mathrm{C}$.

5. Dissolve residue in $20 \mathrm{~mL}$ ethyl acetate, filter through filter paper to remove undissolved solid, and evaporate filtrate to dryness using the rotary evaporator connected to a water aspirator.

6. Dissolve residue in $\sim 20 \mathrm{~mL}$ ethanol with gentle warming $\left(<50^{\circ} \mathrm{C}\right)$. Evaporate to $\sim 10$ $\mathrm{mL}$ using the rotary evaporator connected to water aspirator and cool to $0^{\circ} \mathrm{C}$.

7. Collect crystals of pentafluorophenyl benzoate by filtration through a coarse sintered funnel. Dry material over phosphorus pentoxide in a vacuum desiccator.

8. Store in an amber bottle at $-20^{\circ} \mathrm{C}$ and make sure moisture is excluded (stable for many months).

$$
\text { A yield of } \sim 2.5 \mathrm{~g} \text { product (with a melting point of } 76^{\circ} \text { to } 78^{\circ} \mathrm{C} \text { ) is expected. }
$$

SUPPORT PROTOCOL 3

2'-OH-Protecting Groups That Are Photochemically

Labile or Sensitive to Fluoride Ions

\section{CHROMATOGRAPHIC TECHNIQUES}

Some skill in various techniques of chromatography, both analytical and preparative, are required in these protocols. Reaction mixtures are invariably analyzed by thin-layer chromatography (TLC) on $2 \times 8-\mathrm{cm}$ or $6 \times 8-\mathrm{cm}$ aluminum-backed sheets of Merck silica gel $60 \mathrm{~F}_{254}$ (e.g., EM Science). A $2-\mu \mathrm{L}$ sample of the mixture to be analyzed is applied with a micropipettor in a thin 1-cm line to the origin on the TLC plate. After blowing off excess solvent in a rapidly moving stream of cool air, chromatography is carried out using an appropriate mixture of solvents in a developing jar (e.g., Eastman Kodak). The plate is then dried and placed under short-wave UV light in a viewing box. The products should be visible as well-defined bands against the fluorescent background of the TLC plate. If they are not, the original sample may need to be diluted with acetonitrile or ethyl acetate and reanalyzed. It should also be noted that when the original mixture contains pyridine, as is often the case, the residue of this solvent is visible on the chromatogram as a dark, diffuse band, which can be removed by heating the developed plate in an oven at $140^{\circ} \mathrm{C}$ for a few minutes. This treatment also causes dimethoxytrityl compounds, of which there are many in these protocols, to develop a characteristic yellow color. As a general rule, all reactions and all column fractions should be monitored by TLC. Moreover, it is very important that a reference sample (100 to $200 \mu \mathrm{L}$ ) of each reaction mixture be removed and stored $\left(\right.$ at $\left.-20^{\circ} \mathrm{C}\right)$ for checking against column fractions during the purification process. For additional details on TLC, see APPENDIX 3D.

Preparative chromatographic separations to purify products are carried out on silica gel (e.g., EM Science) packed in glass chromatography columns using the starting solvent. The type and mesh size of the silica gel is important and is specified in each protocol. Columns are generally packed to a bed height of 5 to $10 \mathrm{~cm}$ below their full length to allow loading of the compound mixtures. For additional details on column chromatography, including general packing instructions, see APPENDIX $3 E$. The sample is applied as a narrow band at the top of the column, and products are eluted with increasingly polar solvent mixtures. Many of the separations in this unit are effected using stepwise gradients. A gradient described as, for example, $1.2 \mathrm{~L}$ of $0 \%$ to $10 \%$ methanol in chloroform refers to elution with $200 \mathrm{~mL}$ chloroform, then with $200 \mathrm{~mL}$ of $2 \%$ methanol in chloroform, then with $200 \mathrm{~mL}$ of $4 \%$ methanol in chloroform, and so on up to $10 \%$ methanol in chloroform. At that point, elution is continued with the $10 \%$ solvent mixture, if necessary, until all product is removed from the column, as determined by TLC. The columns are run at such a rate that elution is complete in 6 to $8 \mathrm{hr}$. The eluate emerging from the column is collected as $15-$ to $20-\mathrm{mL}$ fractions in $18 \times 150-\mathrm{mm}$ disposable glass 
culture tubes using a fraction collector. The fractions are then assayed by TLC to locate the desired product. To reduce the number of analyses, every fifth fraction, for example, can be analyzed by TLC, and then these results can be used to narrow down the remaining fractions to assay.

\section{COMMENTARY}

\section{Background Information}

Chemical synthesis of RNA is now almost as simple as that of DNA. However, it requires a specialized set of monomers derived from the four common ribonucleosides $\mathrm{U}, \mathrm{C}, \mathrm{A}$, and $\mathrm{G}$; each of these monomers must carry an extra protecting group to prevent reaction at its $2^{\prime}$ hydroxyl. The protocols in this unit describe the syntheses of two useful sets of protected ribonucleosides. These products are ready to be converted into their corresponding phosphoramidites for use in RNA synthesis (UNIT3.7; Sinha et al., 1993).

\section{2-Nitrobenzyloxymethyl protection}

The first set consists of the $5^{\prime}-O-\left(4,4^{\prime}\right.$-dimethoxytrityl)-2'-O-(2-nitrobenzyloxymethyl) derivatives of $\mathrm{U}$ and of $\mathrm{N}$-protected $\mathrm{C}, \mathrm{A}$, and G. In Basic Protocols 1 and 3, respectively, the readily available nucleosides $\mathrm{U}$ and $\mathrm{A}$ are first converted into their $2^{\prime}, 3^{\prime}$-O-dibutylstannylene derivatives (Wagner et al., 1974). Their $2^{\prime}, 3^{\prime}$ glycol systems are susceptible to monoalkylation after this step. The alkylation is carried out using 2-nitrobenzyl chloromethyl ether and a catalyst, tetra- $n$-butylammonium bromide. This reaction is nonselective, however, and results in formation of the 2'-O-(2-nitrobenzyloxymethyl) derivatives of $\mathrm{U}$ and $\mathrm{A}$ along with equal amounts of their respective $3{ }^{\prime}$-isomers.

In the case of adenosine, the $2^{\prime}$ - and $3^{\prime}$-isomers can be separated chromatographically. The pure 2 '-isomer is isolated and protected at its N6 position by benzoylation, using the transient protection method of Ti et al. (1982). Its $5^{\prime}$-hydroxyl is then protected by reaction with 4,4'-dimethoxytrityl chloride, to give $5^{\prime}-O$ - $\left(4,4^{\prime}\right.$ dimethoxytrityl)-2' $-O$-(2-nitrobenzyloxymethyl)$N^{6}$-benzoyladenosine.

In contrast, the mixture of $2^{\prime}$ - and $3^{\prime}-O-(2-$ nitrobenzyloxymethyl)uridines is first protected at the $5^{\prime}$-hydroxyls, and then chromatographically separated, affording pure $5^{\prime}-O-\left(4,4^{\prime}-\right.$ dimethoxytrityl)-2'-O-(2-nitrobenzyloxymethyl)uridine.

In Basic Protocol 4, guanosine is alkylated after protection of its exocyclic amine with an isobutyryl group (Ohtsuka et al., 1978).
Subsequent conversion to its dibutylstannylene derivative and alkylation in the absence of a catalyst leads to exclusive production of the $2^{\prime}$-O-(2-nitrobenzyloxymethyl) isomer. This material is purified and $5^{\prime}$-protected to give $5^{\prime}-O$ (4,4'-dimethoxytrityl)-2'-O-(2-nitrobenzyloxymethyl)- $N^{2}$-isobutyrylguanosine.

Cytidine, because of the susceptibility of its aminopyrimidone ring to side-alkylation (Wagner et al., 1974), cannot be derivatized in the same way as the other ribonucleosides. Accordingly, some of the $5^{\prime}-O$-(4,4'-dimethoxytrityl)2'-O-(2-nitrobenzyloxymethyl)uridine obtained in Basic Protocol 1 is converted directly into its corresponding cytidine derivative in Basic Protocol 2, using the substitution procedure of Sung (1982). Its N4 amino group is then selectively benzoylated using pentafluorophenyl benzoate (Igolen and Morin, $1980)$ to give $5^{\prime}-O$-(4,4'-dimethoxytrityl)-2'-O(2-nitrobenzyloxymethyl)- $N^{4}$-benzoylcytidine.

After conversion to their respective phosphoramidites, the protected nucleosides can be used in the construction of RNA (UNIT 3.7). The particular advantage of these amidites lies in their short coupling times; they allow RNA to be synthesized almost as rapidly as DNA (Schwartz et al., 1992). Although alternative groups for protecting the 2 -hydroxyls of ribonucleosides are now available that allow coupling times to be reduced nearly to those for protected deoxyribonucleoside phosphoramidites, this was not the case as recently as 3 to 5 years ago. Upon completion of synthesis, the 2-nitrobenzyloxymethyl groups are removed from the resulting oligoribonucleotide products by irradiation with long-wave UV light.

\section{tert-Butyldimethylsilyl protection}

The second set of protected ribonucleosides has the $2^{\prime}$-hydroxyl protected with the tertbutyldimethylsilyl group (Alternate Protocols 1 to 4). This particular group has been used extensively in RNA synthesis (Wincott et al., 1995), and phosphoramidite monomers incorporating it are widely available commercially. The strategy for preparing 2'-O-(tert-butyldimethylsilyl) ribonucleosides in the laboratory
Protection of Nucleosides for Oligonucleotide Synthesis

\subsubsection{3}


differs in a number of respects from that used for the corresponding nitrobenzyloxymethyl derivatives. Again, the starting materials are the four common ribonucleosides, but in this case the exocyclic amines on $\mathrm{C}, \mathrm{A}$, and $\mathrm{G}$ are all protected first. Cytidine is selectively benzoylated at its N4 position with benzoic anhydride in boiling methanol (Watanabe and Fox, 1966); adenosine and guanosine are phenoxyacetylated at their N6 and N2 positions, respectively, using the transient protection method (Ti et al., 1982). These $N$-acyl derivatives and uridine are then dimethoxytritylated to protect their $5^{\prime}$ positions (Hakimelahi et al., 1982; Chaix et al., 1989). The silyl groups are introduced last, by treating the $5^{\prime}-O$-(4,4'-dimethoxytrityl)- $N$-acyl nucleosides with tert-butyldimethylsilyl chloride (Hakimelahi et al., 1982; Chaix et al., 1989). Mixtures of the $2^{\prime}$ - and $3^{\prime}$-isomers are formed in each case, from which the pure $2^{\prime}$ $O$-(tert-butyldimethylsilyl) nucleosides are isolated by column chromatography. They can then be converted into their phosphoramidites using standard procedures (Sinha et al., 1984, 1993).

The tert-butyldimethylsilyl groups can be quantitatively removed from oligoribonucleotides by treatment with tetra- $n$-butylammonium fluoride (Usman et al., 1987). They are also somewhat sensitive to ammonia, however, and their loss during the ammonia treatment that is part of the standard oligoribonucleotide deprotection procedure has caused problems in the past by leading to strand cleavage of the product RNA. Much effort has been expended, therefore, in finding ways to make the ammonolysis conditions less severe. One such method is replacement of the traditional but relatively stable benzoyl and isobutyryl groups on $A$ and $\mathrm{G}$, respectively, with more base-labile ones such as phenoxyacetyl (Chaix et al., 1989) and tert-butylphenoxyacetyl (Sinha et al., 1993). It is the phenoxyacetyl derivatives whose preparation is described in this unit.

\section{Compound Characterization}

Relevant $R_{\mathrm{f}}$ values and available NMR data are shown in Tables 2.5.1 to 2.5.6. Other properties, such as the melting points of crystalline compounds, can be found at the appropriate places in the protocols, and further data are provided in the cited literature. Methods for distinguishing and identifying $2^{\prime}$ - and $3^{\prime}$-isomers of derivatized ribonucleosides by NMR are described in Fromageot et al. (1966) and Chaix et al. (1989).

\section{Critical Parameters}

The success of the operations described here can be affected by a number of critical factors. For example, many of the reagents and reaction mixtures are sensitive to water, and precautions should be taken to exclude moisture. All reactions, unless otherwise specified, should be conducted with dry starting material and anhydrous solvents. The air inlet to the rotary evaporator should be connected to a drying tower, so that no moist air is drawn into the apparatus. If necessary, materials should be co-evaporated with dry solvent a few times before being redissolved in the required reaction volume. Flasks should be opened only long enough for addition or removal of materials, and cold flasks or reagent bottles should always be allowed to reach room temperature before being opened.

Some of the protecting groups used in these protocols are labile, as indeed they are usually designed to be. The 4,4'-dimethoxytrityl group, for example, is removed rapidly under acidic conditions such as those found on some types of silica TLC plates, in silica-gel columns, and as contaminants in solvents such as chloroform. Detritylation and loss of product can be prevented under these circumstances by adding trace amounts of pyridine. The phenoxyacetyl group, on the other hand, is quite base-labile, and alkaline treatments should be strictly limited.

The 2'-O-(tert-butyldimethylsilyl) ribonucleosides should also be treated with care. The tert-butyldimethylsilyl group is known to isomerize between the 2'- and 3'-hydroxyls of the ribose ring in protic solvents such as methanol and in aqueous solutions such as pyridine in water; these environments should be avoided.

The 2-nitrobenzyloxymethyl group is sensitive to UV light and is slowly removed even under normal conditions of laboratory illumination. Exposure of nitrobenzyloxmethyl compounds to UV should be minimized by replacing the overhead white fluorescent bulbs in the work area with yellow ones. Flasks and chromatography columns should be wrapped in foil, and storage containers should be kept in the dark.

The most important consideration of all is the requirement for absolute isomeric purity of the 2'-protected ribonucleosides described here. These products should be examined scrupulously by loading them heavily on TLC plates and looking for the presence of traces of contaminating 3 '-isomer after chromatogra- 
phy. If any of the $3^{\prime}$-isomer is found, the suspect nucleoside should be repurified; it is better to sacrifice a small amount of yield for absolute purity. The consequences of isomeric contamination can be put in perspective by realizing that the presence of the $3^{\prime}$-isomer at a level of $1 \%$ in the monomers means that, for an oligonucleotide 100 units long, not a single molecule is likely to possess all natural $3^{\prime} \rightarrow 5^{\prime}$ linkages.

\section{Anticipated Results}

The experimentalist can expect to obtain one to several grams of each protected nucleoside, ready for phosphitylation and use in an automated synthesizer. By repetition and/or judicious scaling up of the reactions, one can accumulate multigram quantities. Each gram of material corresponds to upwards of 100 nucleotide incorporations on a $0.2-\mu \mathrm{mol}$ synthesis scale.

\section{Time Considerations}

The many partially protected intermediates in these protocols can be safely stored either as crude mixtures ready for chromatographic purification or as purified materials awaiting the next synthesis step. They should be stored in sealed dry containers at $-20^{\circ} \mathrm{C}$ and are stable for many months under these conditions. Within the protocols, each set of preparation and purification steps can be completed in 1 to 2 days, with the following exceptions: preparing the cytidine and benzoylcytidine derivatives in Basic Protocol 2 requires 6 and 7 days, respectively; purifying the isobutyryl guanosine derivative in Basic Protocol 4 requires 3 days; and preparing the tert-butyldimethylsilyl derivatives in Alternate Protocols 3 and 4 requires 4 days. Support Protocols 1 and 2 can be completed in 3 to 4 days and 1 day, respectively. After some familiarity with the methods has been achieved, $\sim 2$ weeks should be required to complete each protocol.

\section{Literature Cited}

Benneche, T., Strande, P., and Undheim, K. 1983. A new synthesis of chloromethyl benzyl ethers. Synthesis 1983:762-763.

Chaix, C., Duplaa, A.M., Molko, D., and Teoule, R. 1989. Solid phase synthesis of the $5^{\prime}$-half of the initiator t-RNA from B. subtilis. Nucl. Acids Res. 17:7381-7393.

Fromageot, H.P.M., Griffin, B.E., Reese, C.B., Sulston, J.E., and Trentham, D.R. 1966. Orientation of ribonucleoside derivatives by proton magnetic resonance spectroscopy. Tetrahedron 22:705710 .
Hakimelahi, G.H., Proba, Z.A., and Ogilvie, K.K. 1982. New catalysts and procedures for the dimethoxytritylation and selective silylation of ribonucleosides. Can. J. Chem. 60:1106-1113.

Igolen, J. and Morin, C. 1980. Rapid synthesis of protected 2'-deoxycytidine derivatives. J. Org. Chem. 45:4802-4804.

Ohtsuka, E., Nakagawa, E., Tanaka, T., Markham, A.F., and Ikehara, M. 1978. Studies on transfer ribonucleic acids and related compounds. XXI. Synthesis and properties of guanine rich fragments from E. coli tRNA ${ }^{\text {fMet }} 5^{\prime}$ end. Chem. Pharm. Bull. 26:2998-3006.

Schwartz, M.E., Breaker, R.R., Asteriadis, G.T., deBear, J.S., and Gough, G.R. 1992. Rapid synthesis of oligoribonucleotides using $2^{\prime}-O$-(2-nitrobenzyloxymethyl)-protected monomers. BioMed. Chem. Lett. 2:1019-1024.

Sinha, N.D., Biernat, J., McManus, J., and Köster, H. 1984. Polymer support oligonucleotide synthesis XVIII: Use of $\beta$-cyanoethyl-N,N-dialkylamino-/N-morpholino phosphoramidite of deoxynucleosides for the synthesis of DNA fragments simplifying deprotection and isolation of the final product. Nucl. Acids Res. 12:45394557.

Sinha, N.D., Davis, P., Usman, N., Perez, J., Hodge, R., Kremsky, J., and Casale, R. 1993. Labile exocyclic amine protection of nucleosides in DNA, RNA and oligonucleotide analog synthesis facilitating $\mathrm{N}$-deacylation, minimizing depurination and chain degradation. Biochimie 75:1323.

Sung, W.L. 1982. Synthesis of 4-(1,2,4-triazol-1yl)pyrimidin-2(1H)-one ribonucleotide and its application in synthesis of oligoribonucleotides. J. Org. Chem. 47:3623-3628.

Ti, G.S., Gaffney, B.L., and Jones, R.A. 1982. Transient protection: Efficient one-flask synthesis of protected deoxynucleosides. J. Am. Chem. Soc. 104:1316-1319.

Usman, N., Ogilvie, K.K., Jiang, M.-Y., and Cedergren, R.J. 1987. Automated chemical synthesis of long oligoribonucleotides using 2'-O-silylated ribonucleoside $3^{\prime}$ - $O$-phosphoramidites on a controlled pore glass support: Synthesis of a 43-nucleotide sequence similar to the 3'-half molecule of an Escherichia coli formylmethionine tRNA. J. Am. Chem. Soc. 109:7845-7854.

Wagner, D., Verheyden, J.P.H., and Moffatt, J.G. 1974. Preparation and synthetic utility of some organotin derivatives of nucleosides. J. Org. Chem. 39:24-30.

Watanabe, K.A. and Fox, J.J. 1966. A simple method for selective acylation of cytidine on the 4-amino group. Angew. Chem., Int. Ed. Engl. 5:579-580.

Wincott, F., DiRenzo, A., Shaffer, C., Grimm, S., Tracz, D., Workman, C., Sweedler, D., Gonzalez, C., Scaringe, S., and Usman, N. 1995. Synthesis, deprotection, analysis and purification of RNA and ribozymes. Nucl. Acids Res. 23:2677-2684.
Protection of Nucleosides for Oligonucleotide Synthesis

2.5.35

Supplement 3 


\section{Key References}

Schwartz et al., 1992. See above.

The general strategy involved in using the 2'-O-(2nitrobenzyloxymethyl protecting group is presented by this method's developers.

Usman et al., 1987. See above.

The general strategy involved in using the 2'-O(tert-butyldimethylsilyl) protecting group is presented by this method's developers.
Wincott et al., 1995. See above.

This publication describes some recent advances in RNA synthesis using the tert-butyldimethylsilyl group.

Contributed by Tod J. Miller, Miriam E. Schwartz, and Geoffrey R. Gough Purdue University

West Lafayette, Indiana
2'-OH-Protecting Groups That Are Photochemically Labile or Sensitive to Fluoride Ions

\subsubsection{6}

